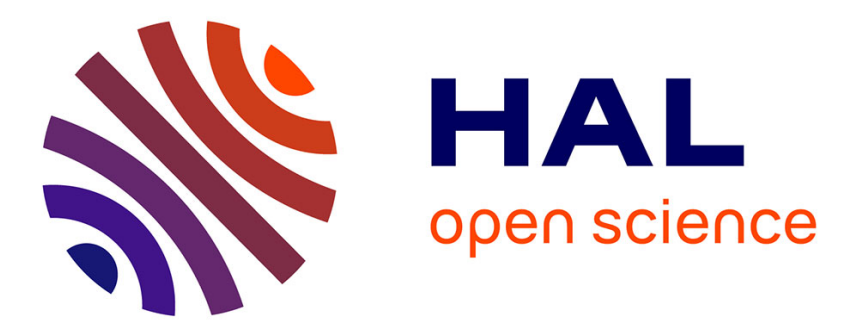

\title{
Development of a Fluid-Structure Coupling Validated with a Confined Fire: Application to Painted Caves
}

Fabien Salmon, Delphine Lacanette, Jean-Christophe Mindeguia, Colette Sirieix, Axel Bellivier, Jean-Claude Leblanc, Catherine Ferrier

\section{- To cite this version:}

Fabien Salmon, Delphine Lacanette, Jean-Christophe Mindeguia, Colette Sirieix, Axel Bellivier, et al.. Development of a Fluid-Structure Coupling Validated with a Confined Fire: Application to Painted Caves. Fire Technology, 2019, 56 (3), pp.1197-1227. 10.1007/s10694-019-00926-5 . hal-03359739

\section{HAL Id: hal-03359739 https://hal.science/hal-03359739}

Submitted on 30 Sep 2021

HAL is a multi-disciplinary open access archive for the deposit and dissemination of scientific research documents, whether they are published or not. The documents may come from teaching and research institutions in France or abroad, or from public or private research centers.
L'archive ouverte pluridisciplinaire HAL, est destinée au dépôt et à la diffusion de documents scientifiques de niveau recherche, publiés ou non, émanant des établissements d'enseignement et de recherche français ou étrangers, des laboratoires publics ou privés. 


\title{
Development of a Fluid-Structure Coupling Validated with a Confined Fire: Application to Painted Caves
}

\author{
Fabien Salmon (10*, Delphine Lacanette, Jean-Christophe Mindeguia and Colette \\ Sirieix, Université de Bordeaux, UMR CNRS 5295 I2M, 16 Avenue Pey \\ Berland, Pessac, France \\ Axel Bellivier, Laboratoire Central de la Préfecture de Police, Rue de Dantzig, \\ 75075 Paris, France \\ Jean-Claude Leblanc, Université de Toulouse, UMR CNRS 5608 TRACES, \\ Allées Antonio Machado, 31058 Toulouse, France \\ Catherine Ferrier, Université de Bordeaux, UMR CNRS 5199 PACEA, \\ Bâtiment B8 Allée Geoffroy Saint Hilaire, Pessac, France
}

\begin{abstract}
In 1994, three speleologists discovered the Chauvet-Pont d'Arc Cave, which contains singular thermal marks on walls deep in the cavity. These alterations arose from intense fires, and understanding their characteristics would help archaeologists suggest hypotheses about the function of such activities. In this context, three confined fires were conducted in a former underground quarry to reproduce thermoalterations similar to those in the Chauvet-Pont d'Arc Cave and extract experimental data. Each fire involved approximately $135 \mathrm{~kg}$ of wood, which was continuously supplied by firemen for safety reasons $\left(>500^{\circ} \mathrm{C}\right)$ and burnt in the shape of a tepee $80 \mathrm{~cm}$ in diameter for $50 \mathrm{~min}$. This paper presents the validation of a numerical model on this experimentation. The modelling requires coupling between the combustion and wall impact simulations. Thus, a link between the combustion code FireFOAM and the thermo-mechanical code Cast $3 \mathrm{~m}$ was created with Python scripts. The results from the simulation agree with the measurements and the observations. More specifically, the analysis is based on the temperatures, gas and particle concentrations, gas velocities, soot deposition, colour changes at the walls and areas likely to spall. These data were collected from thirty-seven measuring points covering the whole quarry. This validated tool will provide information about the features of the fires that occurred within the Chauvet-Pont d'Arc Cave.
\end{abstract}

Keywords: Fire dynamics, Large eddy simulation, OpenFOAM, Thermo-mechanical coupling, Cast3m, Chauvet-Pont d'Arc Cave

\footnotetext{
* Correspondence should be addressed to: Fabien Salmon, E-mail: Salmon.Fabien@yahoo.com
} 


\section{List of Symbols}

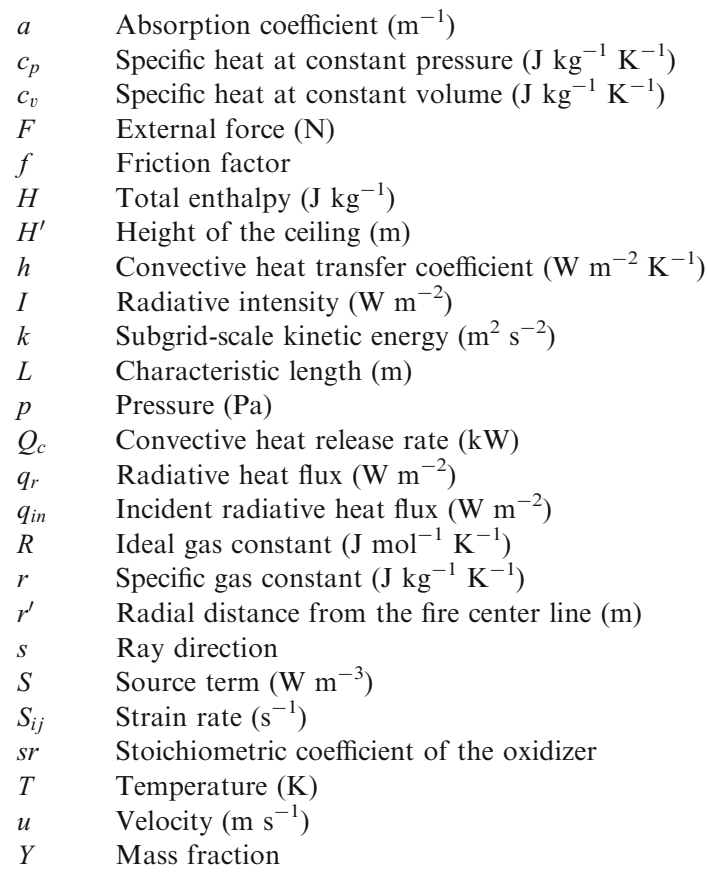

\section{Greek Terms}

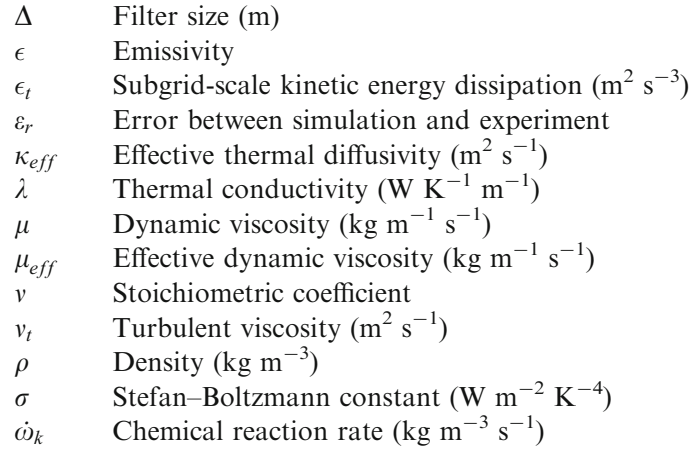

\section{Infroduction}

The interaction between fire and the surrounding structure has been studied in many ways. Among them, fire safety and post-fire analysis foster advances in the numerical simulation of combustion in confined places. Scientists increasingly apply CFD (computational fluid dynamics) simulations to fire modelling for different purposes. Some of the investigations focus on the combustion rather than 
on the impact on neighbouring walls. For instance, Zadeh et al. [1] investigated flame and hot gas behaviour in compartments. Enclosure fires also constitute a wide research field, involving the work of Le et al. [2] and Yuan and Zhang [3]. Risky structures such as underground car parks, tunnels and mines need to be studies in advance to prevent the spread of fire. The use of simulation can resolve these safety matters, such as in [4, 5], which relate to smoke movement and spread of fire among cars. Smoke flows in tunnels were studied numerically and experimentally in [6] by Roh et al. [7] through an FDS (fire dynamics simulator) [8] numerical simulation. Li and Chow investigated fire safety in tunnels [9] and Meng et al. [10] in a subway station. Both employed numerical simulation to estimate the danger arising from fires in confined underground structures. The fire impact on structures can also be the main concern in many applications, such as in [11], which regards the effect of fire on a car park. The behaviour of materials in fire depends on the interaction of the flame with the structures. Luo et al. [12] established a fluid-structure interaction to evaluate the performance of composite materials. There are also many publications on the impact of high temperatures on walls. The spalling of concrete walls is the particular focus in $[13,14]$.

Aside from actual matters, the simulation of the impact of fire on walls is also useful in archaeological applications. The Palaeolithic Chauvet-Pont-d'Arc Cave contains ancient thermal marks on walls; these marks were produced by fires [15, 16]. These alterations include spalling, rubification and grey colour changes (hightemperature chemical reactions). The deposition of soot on walls constitutes other evidence of combustions deep inside the cavity between 37,000 years and 33,500 years ago $[17,18]$. The unusual scale of the fires prevents consensus about their function and archaeologists would like to know the characteristics of these singular fires (amount of wood used, number of fires, locations, etc.) to make assumptions about the purpose of such activities [19]. As a non-intrusive tool, simulation can identify the fires while preserving the cave. Moreover, this approach gives information about the living conditions close to the fire. This question is of interest because it can help archaeologists learn whether the hearths could be supplied during the combustion.

This investigation features a numerical model allowing the simulation of fires and the resulting thermal marks on limestone walls. This model is validated by a fire experiment related to the prior archaeological considerations. The experiment involves creating three similar fires over 3 days (one fire a day) in a former quarry. These fires are intended to challenge the reproducibility of one fire and generate thermo-alterations similar to those in the Chauvet-Pont d'Arc Cave. Several sensors enable the measurement of parameters (temperature, gas velocity, gas and particle concentrations and soot deposition) at different locations. The experimental protocol and the instrumentation are detailed in the second section. This research follows previous works on the modelling of fires in the same quarry [2022].

The third section handles the combustion and fluid mechanics matter. First, the numerical modelling is described. The CFD tool OpenFOAM developed by FM Global [23], and more particularly the FireFOAM solver [24], is adopted to simulate the second fire of the experiment. This tool can conduct studies within irregu- 
lar geometries, which is essential to carry out accurate analyses in caves. Moreover, the open-source nature of this program allows implementations through its $\mathrm{C}++$ framework. Bearing in mind the prehistorical applications that require irregular geometries, the simulation presented in the third section is based on FireFOAM-4.0 with the implementations developed in [22].

The fourth section addresses the thermo-mechanical matter. The thermal investigation aims to describe the colour changes across the walls. Based on experimental observations, criteria about the threshold values from which the alterations become visible are indicated in this section. The mechanical investigation concerns the simulation of stresses in limestone walls generated by thermal expansions due to high temperatures. The simulation of these stresses provides clues about the areas likely to spall. The 2D thermo-mechanical simulations are managed by Cast3m [25], an open-source program developed by the CEA (French Commissariat à l'Energie Atomique). The fire interaction with the surrounding walls requires a coupling between OpenFOAM and Cast $3 \mathrm{~m}$. The framework of the coupling and the mesh achievement are specified in the fourth section.

\section{Experiments Description}

\subsection{Location and Conduct of the Experiment}

The experiment took place within a Rupelian limestone quarry that has no archaeological significance. This gallery is located in Lugasson in Gironde (France). The L-shaped quarry is composed of two nine-meter galleries and the entrance in the first gallery leads to the outside (Fig. 1a). The dimensions are comparable to the Megaloceros Gallery ones in the Chauvet-Pont d'Arc Cave. The fireplace is placed $80 \mathrm{~cm}$ from the back of the second gallery (Fig. 1b). The large entrance area and the hearth's proximity to the outside ensure sufficient ventilation. Thus, oxygen continually supplied the fire despite the confined geometry. According to [26], Aurignacians burnt pinus sylvestris in the Chauvet-Pont d'Arc Cave, so the same fuel is chosen to more closely replicate the archaeological matter.

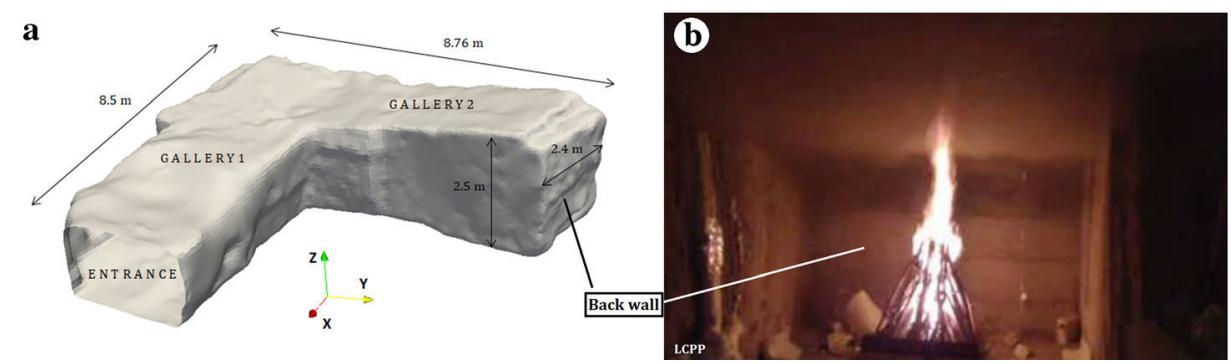

Figure 1. a 3D geometry of the quarry with a $10 \mathrm{~cm}$ resolution achieved by photogrammetry. b The hearth few seconds after the ignition. 
Three fires were carried out with the same protocol. One fire per day was made over 3 days to check the repeatability of such a fire. At the end of each fire, embers were removed from the gallery to reach the usual quarry temperature the very next day.

The fuel was bundled to precisely quantify the amount of wood. Each bundle weighed approximately $4.5 \mathrm{~kg}$ and was composed of branches $80 \mathrm{~cm}$ in length. The branch diameter range represented that for the Scots pine population. All the bundles were therefore similar and well characterized. Their masses were measured before the fires to consider moisture content. Each fire consumed 30 bundles (i.e., $135 \mathrm{~kg}$ of Pinus sylvestris).

The combustion began with 4 bundles that were ignited by a blowtorch. The branches were arranged in a tepee configuration to induce a tall flame and rubify the ceiling. Then, firemen with safety equipment brought bundles in pairs to the hearth while maintaining the tepee shape. The time intervals between each supply were chosen to prevent any decay of the heat release rate during the first fire as much as possible. The same supply times were adopted for the two other fires.

\subsection{Instrumentation}

One objective of the experiment is the validation of the numerical tool. To compare the experiment with the simulation, the quarry was instrumented with sensors. Thermocouples, gas sensors (oxygen, carbon monoxide and dioxide), velocity

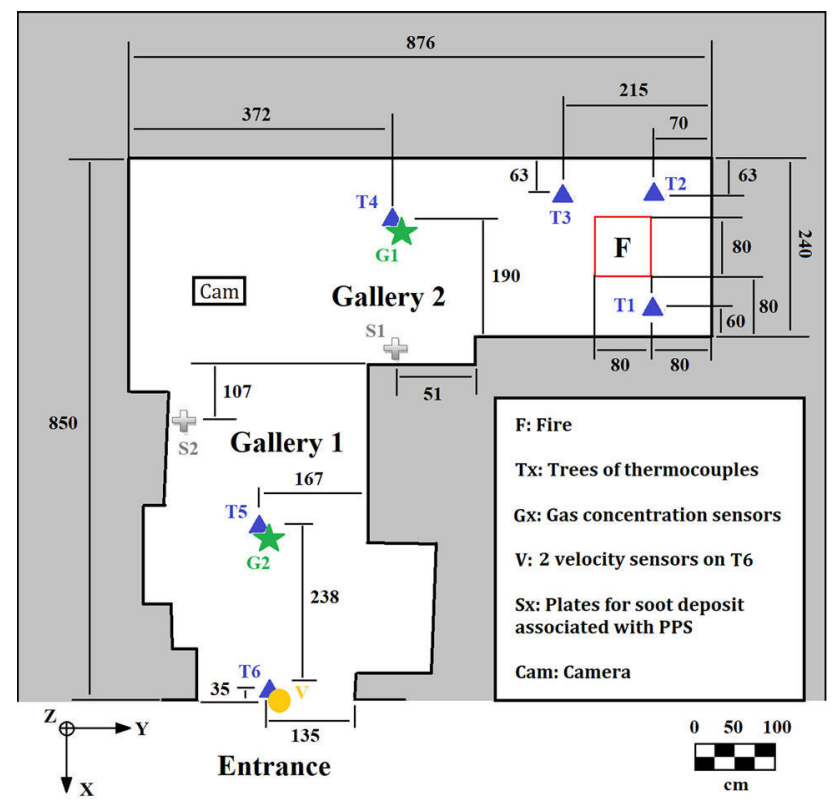

Figure 2. Cutaway view of the instrumented quarry: camera, trees of thermocouples, gas concentration sensors, velocity sensors, plates and PPS locations. 
sensors and Pegasor particle sensors (soot concentration) [27] were positioned within the galleries. The locations of all the sensors are specified in Fig. 2.

The trees of thermocouples were arranged to reach a homogeneous spatial distribution in the quarry. This configuration allows us to obtain experimental data near the fire and in gallery 1 (Fig. 2) to better understand the environmental conditions in a large vicinity of the combustion. In addition, each tree included several vertically distributed thermocouples. Their locations are presented with the results in Sect. 3.3. Twenty-two type-K thermocouples measured the temperature during the experiment. Because they are shielded, radiation only affected them slightly. Without precise information, we make the assumption that the emissivity of all the thermocouples is equal to 0 in the calculations even if a small value could be more accurate. Suction pyrometers could have exactly met this assumption [28]. The gas sensors (Servomex) measured the concentration of three gases (oxygen, carbon monoxide and carbon dioxide) at the two highest thermocouples of trees T4 and T5 and are denoted G1 and G2, respectively. The Pegasor Particle Sensors were situated at points $\mathrm{S} 1$ and $\mathrm{S} 2$. The measurements were made $18 \mathrm{~cm}$ and $16 \mathrm{~cm}$ below the ceiling. Two probes measured the gas velocity at the entrance of the quarry (V on Fig. 2). An ultrasonic anemometer was set $70 \mathrm{~cm}$ above the floor and a McCaffrey probe was set $18 \mathrm{~cm}$ below the ceiling on tree T6. Finally, some targets were fixed on the wall to get back soot particles and estimate the mass of soot deposited by thermophoresis. Three targets were located at $\mathrm{S} 1$ (11 $\mathrm{cm}$ on average below the ceiling) and three others were located at S2 (13 cm on average below the ceiling). A camera, placed in the corner of the cavity, filmed the fires during the experiment.

A weighing scale remained under the hearth during the combustion to measure the mass loss rate. The value of the heat release rate is then deduced from the heat of combustion [29], which is considered constant.

\section{Fluid Mechanics and Combustion}

This section focuses on the fluid and combustion parameters such as the temperatures, gas velocities, soot deposition, and gas and soot concentrations. First, the equations and the resolution methods are detailed. Second, the experimental results are compared with the simulation.

\subsection{Mathematical Description of the Code}

The simulation of the fire is performed by using version 4.0 of FireFOAM [24]. This CFD tool allows the modelling of any combustion through the resolution of the aerothermochemistry equations and the radiative transfer equation.

In addition to the compressible Navier-Stokes equations, FireFOAM solves one conservation equation for each specie [22]. This set of equations is solved with a Lewis number equal to one. This usual hypothesis in such simulations [8] means that the mass diffusion coefficient is equivalent to the thermal diffusion coefficient. The turbulent transports of mass fractions and total enthalpy are modelled by gradients. FireFOAM computes specific heats from Janaf polynomial approxima- 
tions [30]. The modified Eucken correlation [31] ensures the thermal conductivities calculation and Sutherland's law [32] provides the dynamic viscosity.

The chemical reaction rate is modelled by the Magnussen model (eddy dissipation model) [33]:

$$
\dot{\omega}=-\rho C_{c} \epsilon_{t} / k \min \left(Y_{f}, Y_{o} / s r\right)
$$

$C_{c}$ is a model constant, $\epsilon_{t}$ is the subgrid-scale kinetic energy dissipation, $k$ is the subgrid-scale kinetic energy, indices $f$ and $o$ denote the fuel and oxidizer, respectively, and $s r$ is the stoichiometric coefficient of the oxidizer. $C_{c}=20$ gives an accurate numerical heat release rate.

The simulation is based on a constant single step combustion. The wood combustion is assumed to be governed by

$$
\begin{aligned}
\text { Wood }+0.4028 \mathrm{O}_{2}+1.516 \mathrm{~N}_{2}= & 0.3609 \mathrm{CO}_{2}+0.8647 \mathrm{H}_{2} \mathrm{O}+0.0084 \mathrm{CO} \\
& +1.516 \mathrm{~N}_{2}
\end{aligned}
$$

because this chemical reaction leads to consistent gas concentrations.

The mass fraction of soot is managed differently from that of the gases. The mass fraction of soot is proportional to the mass fraction of $\mathrm{CO}_{2}$ through $Y_{\text {soot }} / Y_{\text {soot, } \max }=Y_{\mathrm{CO} 2} / Y_{\mathrm{CO}, \text { max }} . Y_{\text {soot, } \max }$ and $Y_{\mathrm{CO} 2, \max }$ relate to the production of soot and $\mathrm{CO}_{2}$ in the stoichiometric proportions. In the simulation, the stoichiometric coefficient of soot is 0.0015 .

Eventually, the vertical velocity is set to 0 within the quarry except in the turning region $\left(r / H^{\prime}<0.17\right.$ with $r$ the hearth radius and $H^{\prime}$ the ceiling height). This approach is broadly discussed in [22] so only a brief description is proposed here. The hypothesis results from the small energy transfer between the cold and hot layers. Therefore, the vertical velocity must be small, otherwise a non-negligible convective transfer would occur between both layers. As a result, neither the fluctuations of the vertical velocity, nor the vertical transfer which occurs at the walls are considered with this method. Despite these approximations, we demonstrated in [22] that this assumption still improves the accuracy of the simulations. Note that a much finer mesh might have made the vertical velocity hypothesis unnecessary.

Turbulence is modelized by a one-equation model [34] in the LES simulation. The subgrid-scale kinetic energy $k$ is calculated from (2):

$$
\begin{gathered}
\partial \rho k / \partial t+\partial \rho \tilde{u}_{j} k / \partial x_{j}-\partial / \partial x_{j}\left[\mu_{e f f} \partial k / \partial x_{j}\right]=-2 / 3 \rho k \partial \tilde{u}_{k} / \partial x_{k} \\
\quad+\mu_{e f f} \partial \tilde{u}_{i} / \partial x_{j}\left(2 \dot{S}_{i j}-2 / 3 \dot{S}_{k k} \delta_{i j}\right)-C_{\epsilon} \rho k^{3 / 2} / \Delta
\end{gathered}
$$

where $\Delta$ is the filter size directly linked to size mesh and $C_{\epsilon}=1.048$. The turbulent viscosity is calculated from $v_{t}=C_{k} \sqrt{k} \Delta$ with $C_{k}=0.094$. The turbulent thermal diffusivity remains proportional to the turbulent viscosity because the turbulent Prandtl number is set to 0.85 . 
FireFOAM solves the radiative transfer equation (RTE) without regarding the interaction between radiation and turbulence. The grey medium assumption is applied to the gases, and no scattering is considered since the soot concentration remains low in the experiment. The resolution of the RTE [22] yields the radiative intensity $I .30 \%$ of the total energy is considered radiative emission [35]. The absorption coefficient is approximated by a temperature polynomial from the RADCAL model [36].

In such a wood fire, the main process of soot deposition on walls is often thermophoresis. In this mechanism, a great temperature gradient drives particles towards a wall colder than the surrounded gases. The simulation of this phenomenon is based on the thermophoretic velocity $V_{t h}=-K_{\text {th }} \mu_{g} / \rho_{g} \nabla T / T_{g}$ where $K_{t h}$ is the thermophoretic diffusion coefficient. The Beresnev-Chernyak model [37] reaches consistent results according to [38] and [39] so it has been implemented to estimate $K_{t h}$.

\subsection{Computational Setup}

3.2.1. Computational Domain The mesh of the domain was created by "snappyHexMesh" [40] from the quarry geometry acquired by photogrammetry. Here, $3 \mathrm{~cm}$ cells mesh the turning region, $6 \mathrm{~cm}$ cells mesh the remainder of the quarry and $96 \mathrm{~cm}$ cells mesh the outside of the quarry, representing the outside air (Fig. 3). The mesh contains 365,000 cells.

3.2.2. Boundary Conditions The wall temperature results from the balance between heat fluxes:

$$
q_{r}+h\left(T_{g}-T_{w}\right)=\lambda\left(T_{w}-T_{x}\right) / d x
$$

$q_{r}$ is the radiative heat transfer, $h$ is the convective heat transfer coefficient, $\lambda$ is the limestone thermal conductivity, the indices $g, w$ and $x$ correspond to the gas, wall surface and first discretization in the wall respectively and $d x$ is the spatial

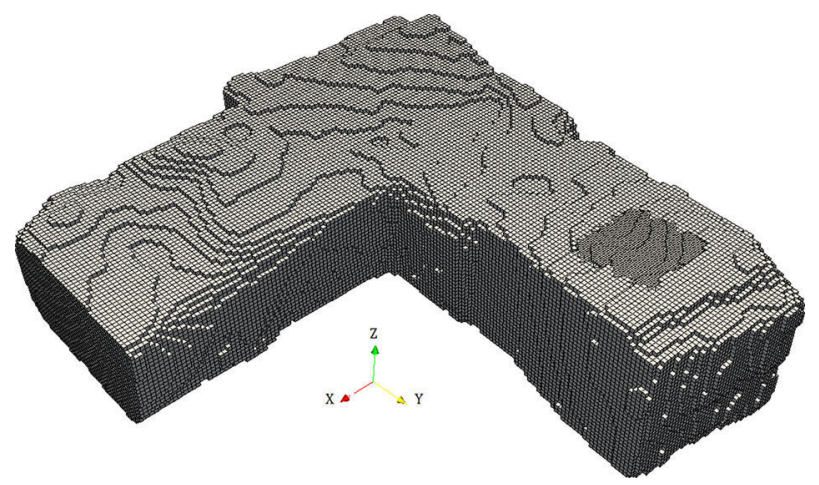

Figure 3. Numerical mesh of the quarry achieved by 
step discretization in the wall. The calculation of the temperature at the first discretization in the wall requires the resolution of the $1 \mathrm{D}$ heat conduction equation for each boundary face. The evaporation of the water contained in the rock pores is considered through a local increase of the specific heat at approximately $100^{\circ} \mathrm{C}$ [22].

The convective heat transfer coefficient is estimated from empirical correlations. At the ceiling, when $0.17<r^{\prime} / H^{\prime}<4$, the Alpert correlation [41] $h=$ $0.246 f\left(Q_{c} / H^{\prime}\right)^{1 / 3}\left(r^{\prime} / H^{\prime}\right)^{-0.69}$ is applied with the convective heat release rate $Q_{c}$ and $f=275$. When $r^{\prime} / H^{\prime}<0.17, h=0.246 f\left(Q_{c} / H^{\prime}\right)^{1 / 3} 0.17^{-0.69}$. The value of $f$ is different from the one in [22]. This modification is necessary to make the simulated thermo-alterations match with the observations. Only the temperature of the walls is strongly affected by this change while the gas temperature remains weakly impacted. This formulation is originally intended for an unconfined ceiling; however, we consider that the confinement does not affect the trend and only affects the proportional coefficient $f$ [42]. Elsewhere, the Nusselt number correlations for planes are applied [43]. The convective heat transfer coefficient is then deduced by $h=N u \lambda / L$, with $L$ as a characteristic length. Usually, $L=1$ metre is chosen in CFD codes (FDS [8] for instance), so this value is selected for the cold layer. However, in the hot layer, the simulation requires $L=1 \mathrm{~mm}$ for the numerical rubified area to match the experimental one. Numerically, the limit between both layers is assumed to be $400 \mathrm{~K}$. Below $400 \mathrm{~K}$, the length is one metre, whereas it is one millimetre above $400 \mathrm{~K}$. The previous choices for the heat transfer coefficients are thoroughly explained in [22].

The temperature of the outside walls is set at the initial temperature of $12^{\circ} \mathrm{C}$. The velocity is nil at all the walls.

3.2.3. Numerical Method OpenFOAM solves the aerothermochemistry equations with finite volumes. The simulation considers a maximum CFL (Courant-Friedrichs-Lewy) number of 0.6 . The pressure calculation is managed by the pressurecorrection method PISO (Pressure Implicit with Splitting of Operator). FireFOAM performs 10 flow iterations between each radiation resolution. The finite volume discrete ordinates method with 32 solid angles ensures the resolution of the RTE.

To compare the experimental data with the simulation results, a correction must be applied to the simulated gases because the thermocouple temperature is not equal to the gases one. The heat flux balance provides the following equation on the thermocouple temperature $T$

$$
\rho c_{p} V \partial T / \partial t=\epsilon\left(q_{\text {in }}-\sigma T^{4}\right) A+h\left(T_{g}-T\right) A
$$

with $V$ the thermocouple volume, $A$ the thermocouple area, $\epsilon$ the thermocouple emissivity and $q_{\text {in }}=\int_{s \cdot n<0} I(r, s) s \cdot n d \Omega$ the incident radiative flux. The simulated gas temperatures are corrected by (4) and then compared with the experimental temperature. 
The simulation was performed by 96 processors on a Bullx DLC server with $4 \times 24$ core Intel Haswell-EP Xeon 12-Core E5-2690 V3 2.6 GHz. Four days are necessary to achieve the simulation of $50 \mathrm{~min}$ of fire.

\subsection{Comparison Between Experimentation and Simulation}

This part addresses the comparison between the numerical and experimental results in the air of the quarry. The average error on a variable $v$ will be estimated by $\varepsilon_{r}=\frac{\left|v_{\text {exp }}-v_{\text {simu }}\right|}{v_{\text {exp }}}$ as long as this information is meaningful.

The locations of each tree are detailed in Fig. 2. For each tree of thermocouples, one graph compares the experimental and simulation results for all the thermocouples. On the right of each graph, the vertical locations of the thermocouples are detailed. Each of them corresponds to a different colour in the graphs.

The results for tree T1 are shown in Fig. 4. A significant separation between the cold and hot layers takes place during most of the combustion. The formation of two distinct layers is usual in open geometries [8]. In the hot layer, the temperature is accurately described because it remains in the good order of magnitude until the end of the combustion $\left(\varepsilon_{r}=17 \%\right)$. The largest difference occurs between $15 \mathrm{~min}$ and $30 \mathrm{~min}$ after ignition, with local differences of $100^{\circ} \mathrm{C}$. Regarding the cold layer, the simulation gives consistent temperatures until $30 \mathrm{~min}$ after ignition. Then, the thermocouple seems to measure the temperature of the hot layer because of its thickening. However, in the simulation, the cold layer still surrounds T1_2 until the end of the combustion. This difference could have manifold geometric origins: the photogrammetry process (laser inaccuracies), resolution, mesh and thermocouple positions. Then, the comparison between the measurements and simulation results may be made at different vertical locations due to
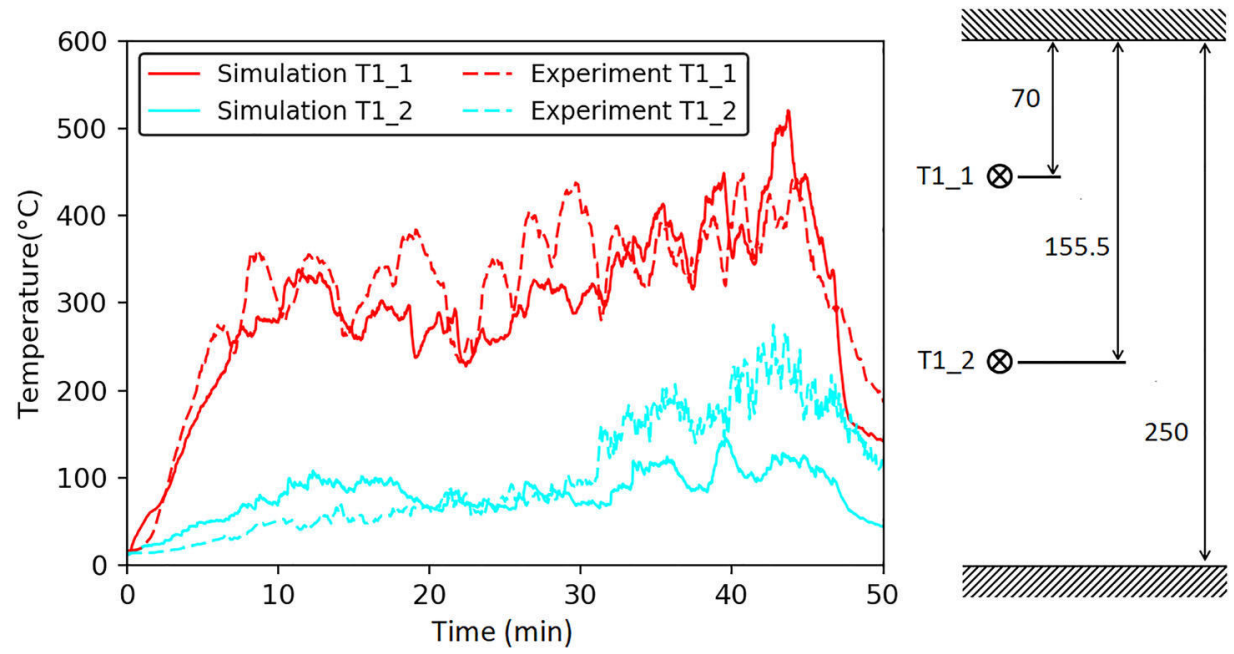

Figure 4. On the left: numerical and experimental temperatures at tree T1. On the right: vertical thermocouple locations (in $\mathrm{cm}$ ). 
these uncertainties. Because the limit between the layers is home to strong temperature gradients, a gap of a few centimetres could lead to very different temperatures. In addition, the type- $\mathrm{K}$ thermocouples present uncertainties: $\pm 2^{\circ} \mathrm{C}$ for weak temperatures and $<5^{\circ} \mathrm{C}$ in the hot layer.

Note that deviations of tens of percent are quite common in fire simulations due to the complex physico-chemical phenomena. For instance, the difference between the experiments and simulations focused on flames is often superior to $20 \%$ [44-46]. Other simulations of flames interacting with a wall or ceiling also lead to substantial gaps up to $40 \%[47,48]$. Therefore, the simulation presented in this paper, on a larger scale, is reliable around $\mathrm{T} 1$.

Figure 5 shows the comparisons for tree T2. At the same height, the gases are broadly warmer around tree T2 than tree T1. The gases around T2_2 are 10\% hotter than those around T1_1 between 10 and $50 \mathrm{~min}$ (without the transition phase). The same gap is observed between the gas temperatures at T2_4 and T1_2 between $10 \mathrm{~min}$ and $30 \mathrm{~min}$. Because T1 is supplied by outside fresh air before T2 (Fig. 2), the second tree measures gases hotter than $\mathrm{T} 1$; thus, the temperature remains higher.

The simulation reproduces the temperature homogeneity of the hot layer since the temperatures at T2_1 and T2_2 (Fig. 5) are very similar. The average errors are both inferior to $22 \%$. The thermocouple T2_3 does not allow comparison because it remains between both layers during most of the combustion. Therefore, the temperature gradient is very high in this area and a few centimetres can greatly modify the measurement. Then, a good fit between the experiment and simulation cannot be expected. For the last three thermocouples in the cold layer, the same conclusion as the one for tree $\mathrm{T} 1$ can be made. At the end of the fire, no clear distinction between two layers can be defined and the vertical temperature
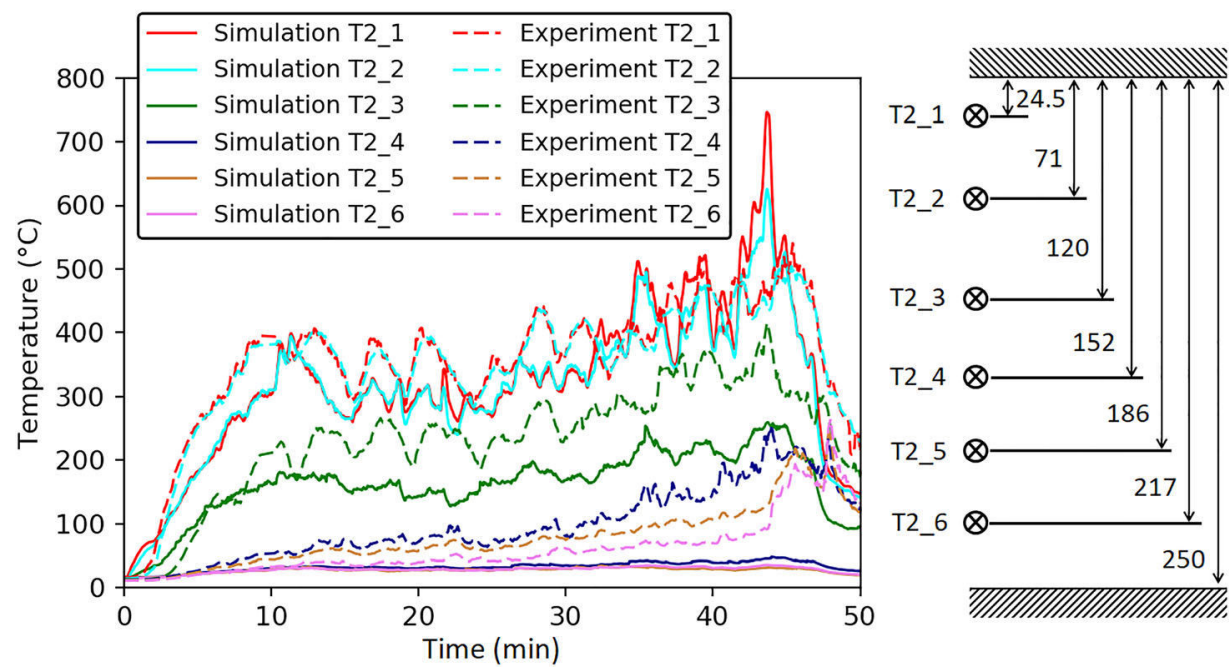

Figure 5. On the left: numerical and experimental temperatures at tree T2. On the right: vertical thermocouple locations (in $\mathrm{cm}$ ). 
gradient appears less strong than in the simulation. The obstruction of the gas circulation by the back wall may explain this experimental observation. Cooper [49], who studied ceiling jet-driven wall flows, detailed the process leading the gases from the hot layer to the cold one. This mechanism necessarily happens at the back wall due to its proximity to the fire. Based on the hypothesis of an exclusive horizontal velocity (Sect. 3.1), the simulation cannot reproduce such an effect, so it underestimates the temperatures of the three lowest thermocouples.

Figure 6 shows the results for tree T3. The simulation again provides a homogeneous temperature in the hot layer and the simulated hot layer temperature is satisfactory. Similar to tree T1, the simulated temperature is too weak between $15 \mathrm{~min}$ and $30 \mathrm{~min}$. However, the gap remains acceptable since the average errors are $\varepsilon_{r}=21 \%$ and $\varepsilon_{r}=26 \%$ for T3_1 and T3_2, respectively. Contrary to the simulation, the hot layer reaches thermocouple T3_3 after $30 \mathrm{~min}$. However, the simulation was very close to the experiment during the first $30 \mathrm{~min}$. Moreover, the experimental temperature at T3_4 reaches the simulated temperature at T3_3. Then, at the end of the combustion, the hot layer at T3 in the simulation seems to be thinner than the experimental one. This could explain why the experimental temperatures are always superior to the simulated ones.

Figure 7 displays the results for tree T4. Experimentally, a large gap exists between the measured temperatures at T4_1 and T4_2. This gap is different from that of tree T3 despite the same vertical distance between the corresponding thermocouples. However, T4 is further than T3 from the fire, and according to the measurements, the hot layer is thinner at $\mathrm{T} 4$ than at $\mathrm{T} 3$. This observation results from the ceiling height which depends on the location in the quarry. Because the borderline between both layers must be nearly at the same height in the second gallery, the hot layer is thinner (as well as the cold layer) at T4 than at T3. In the
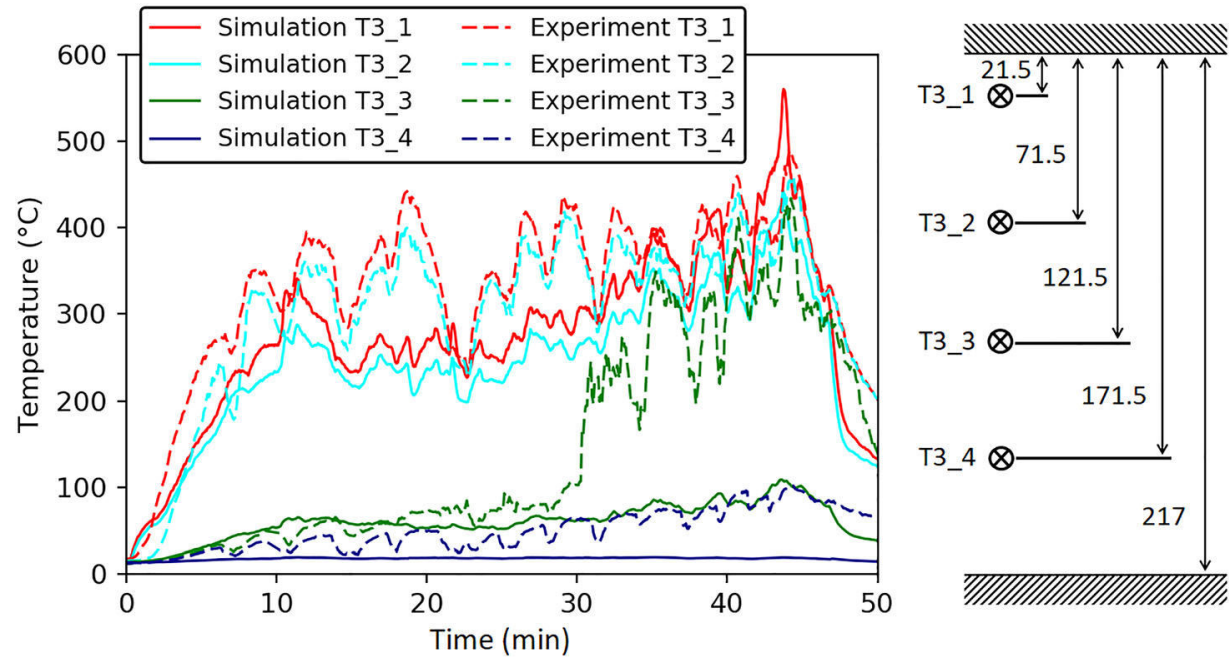

Figure 6. On the left: numerical and experimental temperatures at tree T3. On the right: vertical thermocouple locations (in $\mathrm{cm}$ ). 

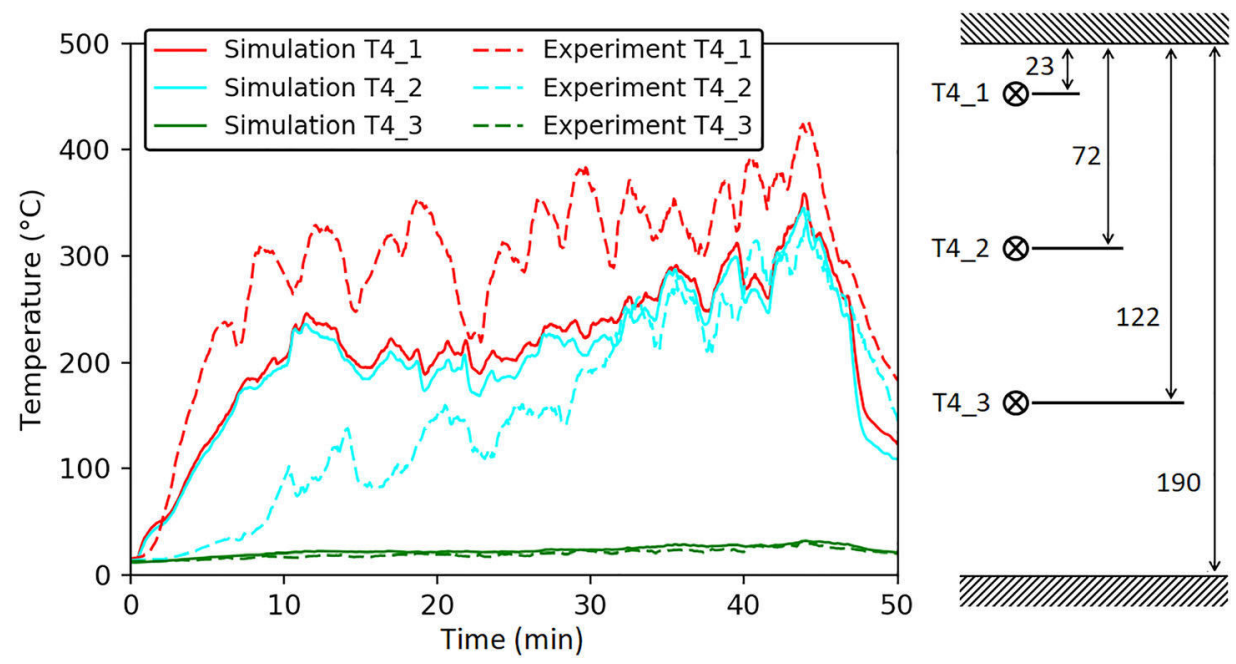

\section{Figure 7. On the left: numerical and experimental temperatures at tree T4. On the right: vertical thermocouple locations (in $\mathrm{cm}$ ).}

simulation, the hot layer is slightly thicker than the experimental one for at least the first $30 \mathrm{~min}$. Indeed, the measured temperature at T4_2 reaches the simulated temperature T4_2 only after half an hour. The difference between the experimentation and simulation for the higher thermocouple temperature could result from the thickness of the layer. Because the hot layer is thicker in the simulation, the energy is less concentrated and the temperature is lower than if the layer was thinner. The hot layer temperature error averages $30 \%$, but the difference is greater during the first half of the combustion. Note that the overestimation of the hot layer thickness could stem from the temperature boundary conditions. The heat transfer to walls is estimated by the model described in Sect. 3.2.2. This model is based on the observations of the thermal impacts after the experiment (Sect. 4.4.1). However, this model could inaccurately describe the heat transfer far from the fire, where the ceiling jet-driven wall flows process does not occur strongly. Then, the wall temperatures in the hot layer could be amplified by the simulation from tree $\mathrm{T} 4$ to the entrance to the cavity. This deviation could lead to a thicker hot layer. Moreover, the vaporization of water may be inaccurate because this phenomenon is difficult to evaluate. Then, the simulation could underestimate the energy required by the vaporization and overestimate the surface temperature. As regards the cold layer, the simulation provides satisfying temperatures.

Similarly, Fig. 8, which shows the results at tree T5, reveals a hot layer that is too thick in the simulation and an overestimation of the temperature until the end. Close to the entrance, the homogeneity of the hot layer temperature can be disputed since the simulation underestimates the hot layer temperature at the previous trees, which is contradictory. In the experiment, the temperature should be higher closer to the ceiling and the simulated temperature could be in agreement 


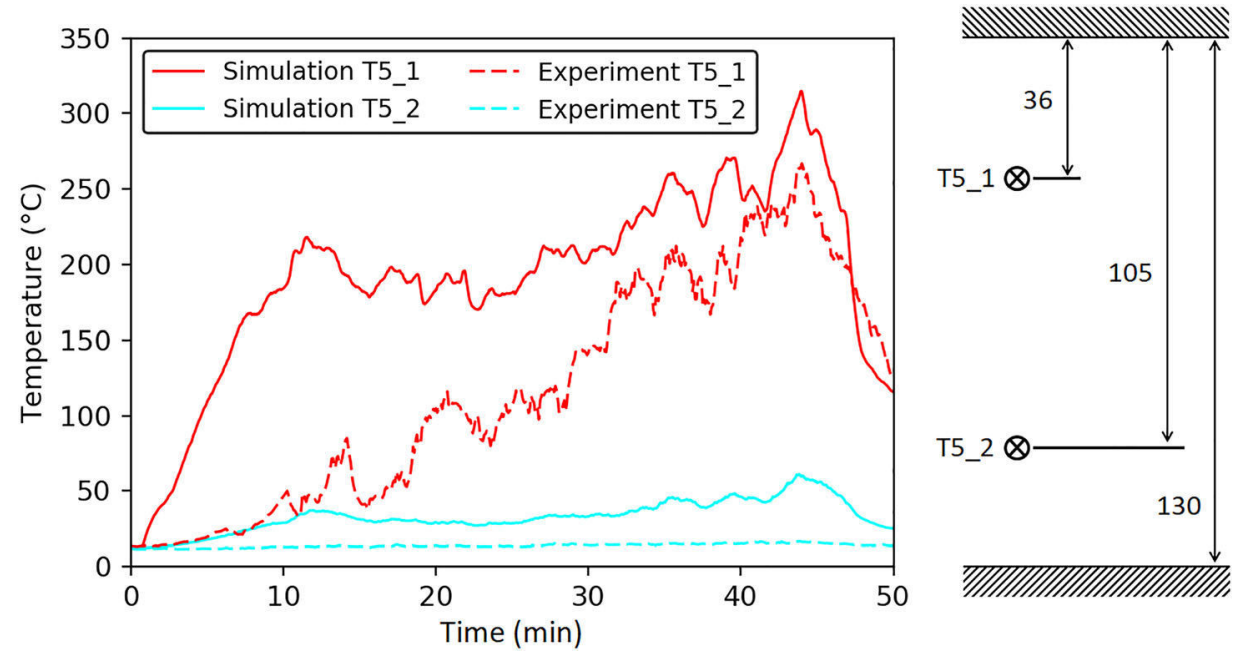

\section{Figure 8. On the left: numerical and experimental temperatures at tree T5. On the right: vertical thermocouple locations (in $\mathrm{cm}$ ).}

with a measurement very near the ceiling. However, during the experiment, the hot layer thickens and the measured temperature at T5_1 ends up catching the simulation. The explanation about the heat transfer to the walls detailed previously could apply to the temperature gap. The simulated temperature in the cold layer is slightly affected by the fire, in contrast to that in the experiment. The temperature remains below $50^{\circ} \mathrm{C}$ in the simulation. The measurements report that the incoming air is still at approximately $10^{\circ} \mathrm{C}$ at $\mathrm{T} 5 \_2$. The difference may derive from a rough assessment of the inflow rate since the hot layer is too thick. The error is not prohibitive in this study because $50^{\circ} \mathrm{C}$ is generally not dangerous for humans. The danger could appear under saturated air which was not the case in the simulation due to the gas circulation with the outside air. This matter is essential for applying the model to the Chauvet-Pont d'Arc Cave.

Finally, Fig. 9 describes the temperature at the entrance of the quarry. The temperature just below the ceiling is simulated correctly and the error remains very low until the end of the combustion $\left(\varepsilon_{r}<24 \%\right)$. The gap is higher for thermocouple T6_2. Actually, the hot layer becomes even thinner where the gases are evacuated. Not only is the hot layer too thick in the simulation, but it is not thinner at the exit. Consequently, the temperatures in the upper part are overestimated. This inaccuracy affects the results of the thermocouples T6_2, T6_3 and perhaps T6_4. On the floor, the incoming air remains at approximately $10^{\circ} \mathrm{C}$ in the simulation, as expected $\left(\varepsilon_{r}<12 \%\right)$.

The gas concentrations are analysed at locations T4_1 and T5_1. Figure 10 displays the comparison at T4_1 for dioxygen, carbon monoxide and carbon dioxide. $\mathrm{Ne}$ that the measurement uncertainty remains inferior to $1 \%$ for this kind of sensor. The simulated orders of magnitude for the three gases are consistent with the experimentation. The trends are well described until the end for carbon dioxide 


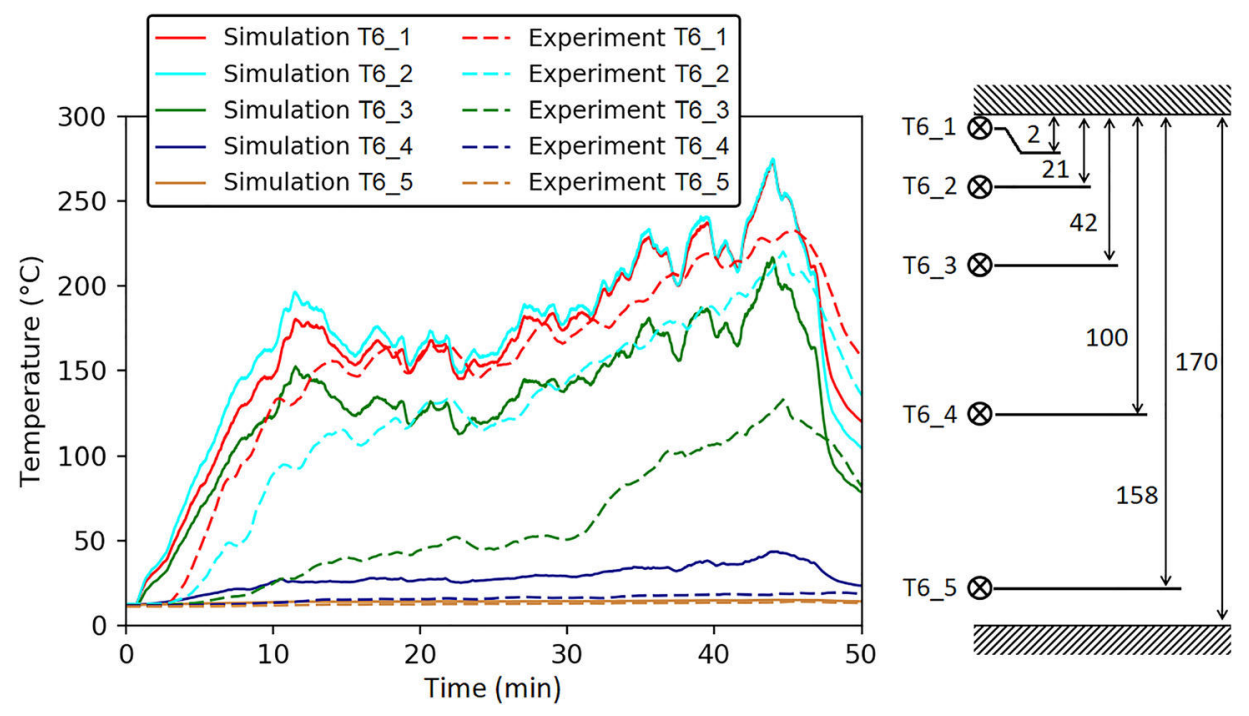

Figure 9. On the left: numerical and experimental temperatures at tree T6. On the right: vertical thermocouple locations (in $\mathrm{cm}$ ).

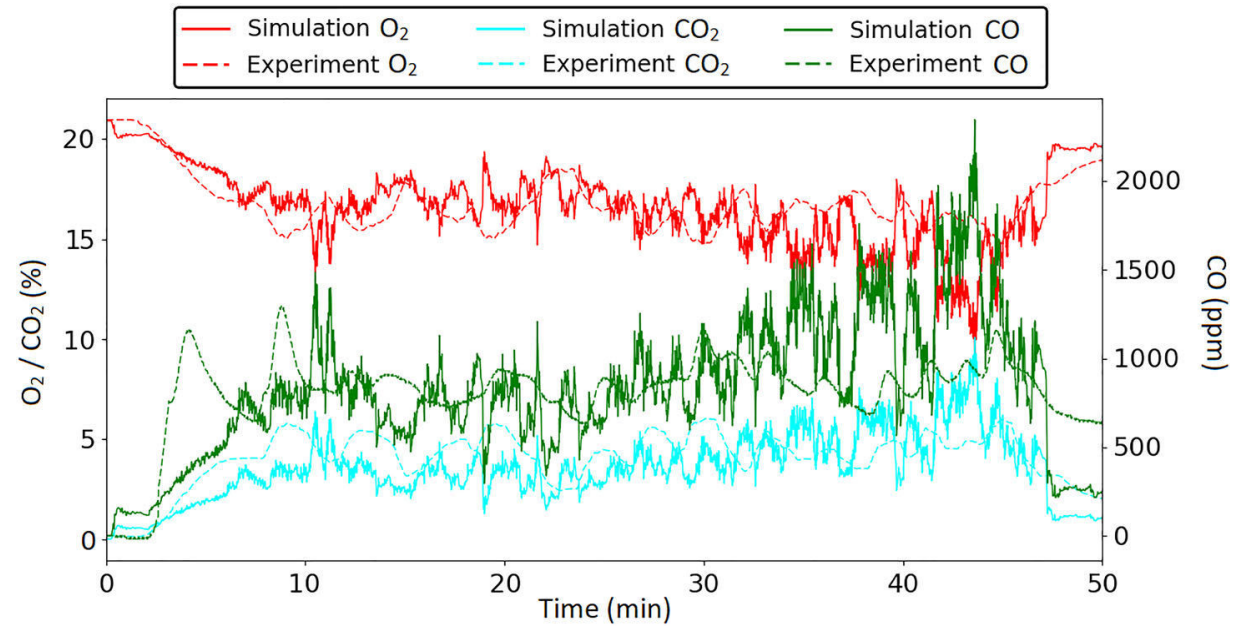

\section{Figure 10. Numerical and experimental gas concentrations (dioxygen, carbon monoxide and carbon dioxide) at C1 (Fig. 2).}

and dioxygen despite a little drop after 40 min which does not occur experimentally. The simulation yields satisfactory concentrations for carbon monoxide for $35 \mathrm{~min}$. Then, the concentration oscillates greatly. The average of these oscillations slightly overestimates the experimental carbon monoxide concentration. On average, the errors remain satisfactory for this kind of simulation: $\varepsilon_{r, \mathrm{O}_{2}}=7 \%$ and $\varepsilon_{r, \mathrm{CO}_{2}} \sim \varepsilon_{r, \mathrm{CO}} \sim 30 \%$. The source of errors is probably the same as the one dis- 


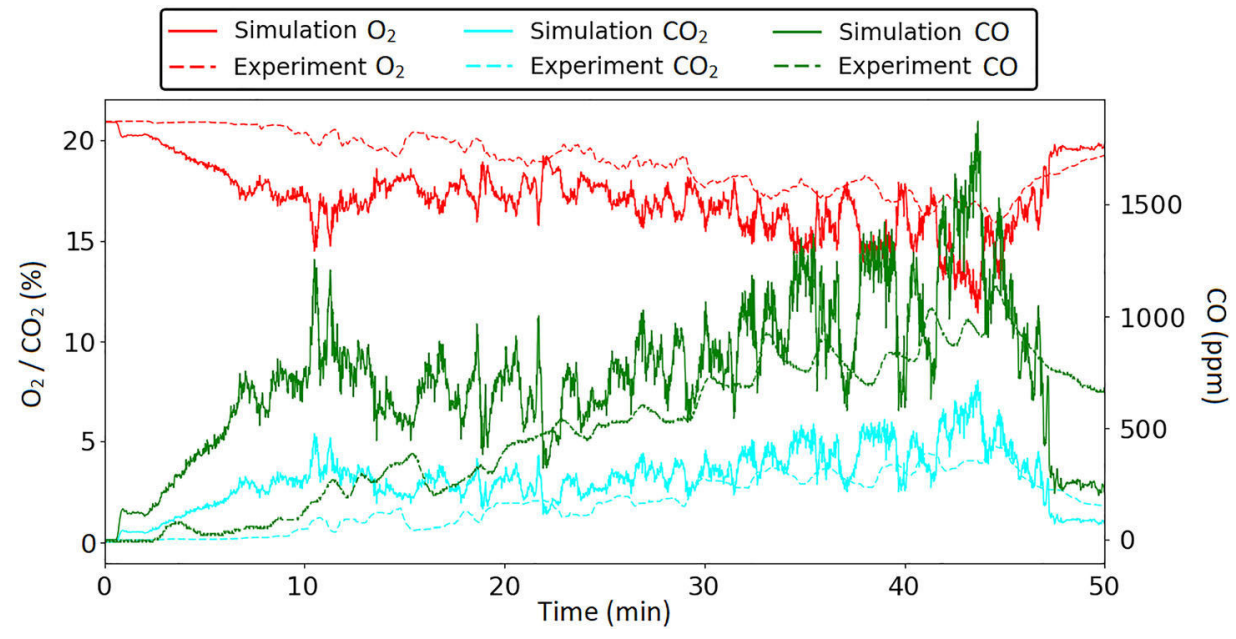

\section{Figure 11. Numerical and experimental gas concentrations (dioxygen, carbon monoxide and carbon dioxide) at C2 (Fig. 2).}

cussed for the temperature at T4_1. In addition, the relative error between the simulation and experiment is the same for the temperature and gas concentrations of $\mathrm{CO}_{2}$ and $\mathrm{CO}$.

Figure 11 provides the comparison of the gas concentrations at T5_1. All the numerical concentrations are subject to strong variations during the first $20 \mathrm{~min}$, which do not occur experimentally. These differences are due to the thickness of the hot layer, as previously demonstrated for tree T5. The hot layer is thicker in the simulation and the location T5_1 remains in the hot gases throughout the combustion. The possible sources of the deviation were detailed with the temperature comparison of tree T5. Experimentally, T5_1 remains in fresh air for several minutes. However, $20 \mathrm{~min}$ after ignition, the concentrations come close to the experimental ones. Then, the same conclusions as for the concentrations at T4_1 can be drawn. There is little overestimation of the simulated carbon monoxide after $35 \mathrm{~min}$. A small drop exists for dioxygen after $40 \mathrm{~min}$, while carbon dioxide is simulated aptly. The simulation underestimates the dioxygen concentration by approximately $10 \%$. Without accounting for the first $20 \mathrm{~min}, \mathrm{CO}_{2}$ is overestimated by more than $40 \%$ and $\mathrm{CO}$ by $36 \%$.

Figure 12 compares particle concentrations at two points, PPS1 and PPS2 (Fig. 2). The simulated soot concentration at PPS1 is accurate until the end of the combustion $\left(\varepsilon_{r}=27 \%\right)$. A peak occurs just after ignition due to the crossing of water vapor initially contained in wood. PPS2 is a fringe location, so the water vapor at the sensor is low. The simulation overestimates the soot concentration until the end of the simulation and the error increases as the combustion progresses $\left(\varepsilon_{r}=88 \%\right)$. The position of the Pegasor Particle Sensor could explain such a difference between simulation and experimentation. Because the hot layer is overestimated in the simulation, the sensor is not in the lower part of the hot layer, contrary to the observation. Therefore, the simulation leads to inaccuracies 


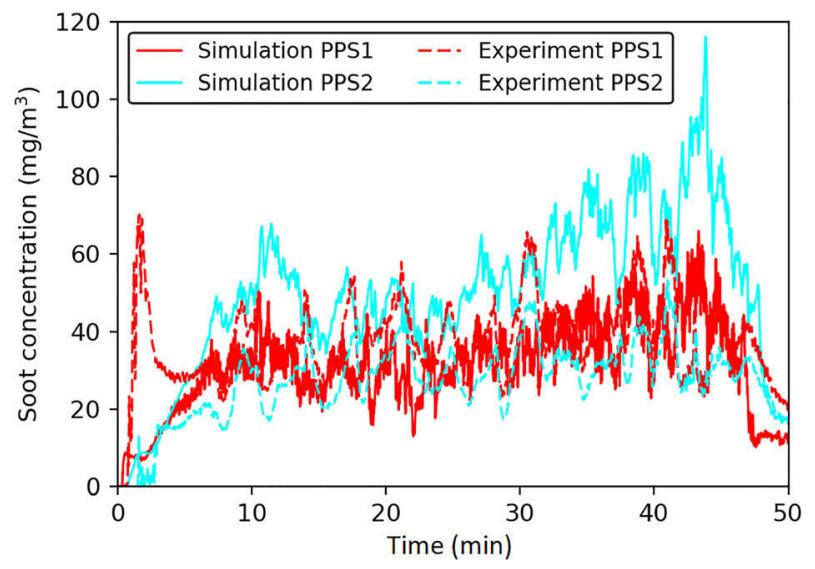

Figure 12. Numerical and experimental soot concentrations at $\mathrm{S} 1$ and 52 (Fig. 2).

at this point. The temperature boundary conditions should then increase the inconsistency in the soot concentration, as described above.

The velocities of gases in the hot and cold layers at the entrance of the quarry are plotted in Fig. 13. The hot layer velocity and the global trend are simulated correctly. Ignoring the first $5 \mathrm{~min}$, since the sensor fails to measure in this time interval, the average error is $29 \%$. Because of the mistake in terms of the thickness of the hot layer, the mass conservation requires a smaller velocity in the simulation than in the experiment. This leads to an underestimation of the velocity of

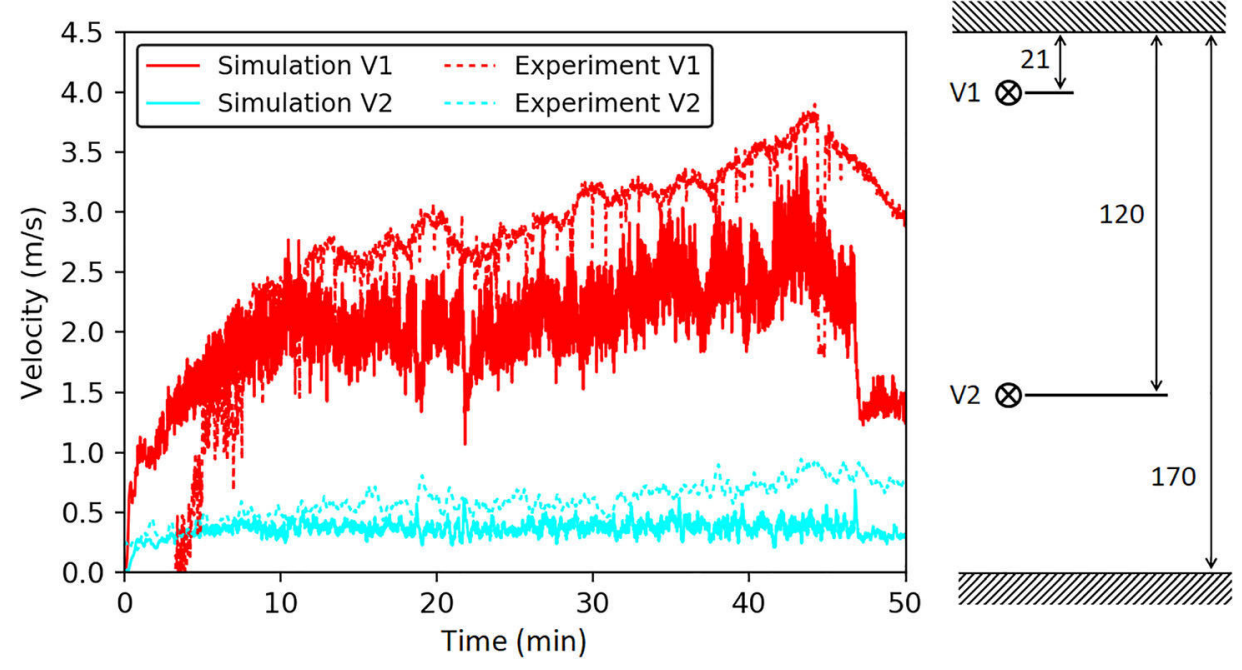

Figure 13. On the left: numerical and experimental velocities at tree T7. On the right: vertical probe locations (in $\mathrm{cm}$ ). 
gases in the cold layer $\left(\varepsilon_{r}=37 \%\right)$ for the same reason. Nonetheless, this velocity remains consistent within an order of magnitude during the beginning of the fire. Note that the uncertainties in the data cannot explain the entire gap. The uncertainty of the McCaffrey probe (in the hot layer) is slightly affected by its orientation [50] $(<10 \%)$ while the ultrasonic anemometer (in the cold layer) is accurate to within $0.05 \mathrm{~m} \mathrm{~s}^{-1}$.

Eventually, the simulated soot deposition is compared with the average soot deposition over the three targets for locations S1 and S2 in Table 1. At S1, the simulation provides an appropriate mass since the error is approximately $15 \%$. However, the simulation widely yields an underestimation of the soot mass at S2. In addition, the soot concentration was overestimated by the simulation. Then, an overestimation of the soot deposit at S2 was expected, rather than an underestimation. At first sight, this simulation seems to fail to calculate the mass of the soot deposited on the walls. However, the standard deviation over the three fires is approximately $1 \mathrm{mg}$ for both locations. Then, the measurements of the soot deposits are also inaccurate and the comparison with the simulation can only be made in terms of the order of magnitude of the deposited mass. From this perspective, the simulation leads to masses that are similar to those in the experiment (more or less than $1 \mathrm{mg}$ ), despite a coarse grid at the boundary. The grid size indeed greatly affects the amount of deposited soot, as shown by Overholt et al. [51]. A better refinement and a wall-resolved large eddy simulation or a direct numerical simulation would have been necessary to accurately simulate the soot quantity.

\section{Thermo-mechanical Coupling}

This section describes the heat diffusion and mechanical stresses in the quarry walls. First, the thermal marks resulting from the fire impact are detailed. Second, the modelling is briefly discussed. Third, the coupling between Cast3m [25] and OpenFOAM [23] and the transfer of data between them are described [52]. Last, the observations are compared with the simulation.

\subsection{Effects of Temperature on Limestone Walls}

4.1.1. High-Temperature Chemical Reaction Characterization The fires can affect limestone walls thermally through chemical reactions. The first reaction changes

\section{Table 1}

\section{Numerical and Experimental Soot Deposit at S1 and S2}

\begin{tabular}{lcccc}
\hline Locations & $\begin{array}{c}\text { Simulation } \\
(\mathrm{mg})\end{array}$ & $\begin{array}{c}\text { Experiment (fire 2) } \\
(\mathrm{mg})\end{array}$ & $\begin{array}{c}\text { Experiment (average) } \\
(\mathrm{mg})\end{array}$ & $\begin{array}{c}\text { Experiment (SD) } \\
(\mathrm{mg})\end{array}$ \\
\hline S1 & 0.72 & 0.84 & 1.38 & 1.05 \\
S2 & 0.54 & 3.09 & 2.12 & 1.03 \\
\hline
\end{tabular}


the rock colour to red by iron oxide release. This chemical process, called rubification, involves a transformation of goethite to haematite [53, 54]. Experimental observations showed that rubification becomes apparent after heating at $250^{\circ} \mathrm{C}$ for $10 \mathrm{~min}$ [55]. In the simulation, this criterion will specify the rubification threshold. The second reaction makes limestone grey at higher temperatures [56, 57]. Laboratory tests on Rupelian limestone showed that maintaining $450^{\circ} \mathrm{C}$ for $10 \mathrm{~min}$ is required for this colour change.

4.1.2. Spalling The low thermal diffusivity of limestone yields high temperature gradients in the quarry walls during a fire. These temperature gradients produce high stresses in the rock through dilatation differences. This process leads to buckling ejection of limestone from the walls [58]. This detachment, called spalling, could also derive from pore pressure changes due to the vaporization of water. This investigation assesses the areas likely to spall due to excessive temperature gradients and the thermo-hydric processes are not discussed.

\subsection{Modelling}

The thermo-mechanical behaviour is managed by Cast3m [25]. This finite element software first solves the heat diffusion problem (with the Fourier law) and then solves the mechanical problem (small deformation theory) for each time step. The limestone is considered thermo-elastic in addition to thermally and mechanically isotropic. A 2D approach is chosen because a 3D simulation would be time-consuming. The plane deformation hypothesis is applied to 2D geometries corresponding to sections of the 3D geometry.

The properties of Rupelian limestone depend on the temperature. The thermal and mechanical properties of Rupelian limestone are summarized in Tables 2 and 3 , respectively [20].

\subsection{Coupling Between Cast3m and OpenFOAM}

The modelling of the impacts of fire on walls requires that a weak coupling between OpenFOAM and Cast $3 \mathrm{~m}$ be set up. The Python code is provided online [52]. The wall temperatures from OpenFOAM are used in Cast $3 \mathrm{~m}$ as boundary conditions. The impact of wall heating on the combustion progress is not considered in this coupling to save time. However, OpenFOAM accounts for the increasing temperature of the walls during the fire through Eq. (3) and the resolution of the 1D heat equation for all the boundary faces (Sect. 3.2.2).

\section{Table 2}

Thermal Properties of Rupelian Limestone According to Temperature

\begin{tabular}{lllllllll}
\hline Temperature $\left({ }^{\circ} \mathrm{C}\right)$ & 20 & 95 & 100 & 120 & 200 & 300 & 400 & 500 \\
Thermal conductivity $\left(\mathrm{W} \mathrm{m}^{-1} \mathrm{~K}^{-1}\right)$ & 0.74 & 0.55 & 0.54 & 0.52 & 0.43 & 0.37 & 0.31 & 0.25 \\
Density $\left(\mathrm{kg} \mathrm{m}^{-3}\right)$ & 1675 & 1675 & 1675 & 1670 & 1660 & 1635 & 1565 & 1520 \\
Specific heat $\left(\mathrm{J} \mathrm{kg}^{-1} \mathrm{~K}^{-1}\right)$ & 669 & 1266 & 7232 & 7232 & 1446 & 1600 & 1700 & 1850 \\
\hline
\end{tabular}


Table 3

Mechanical Properties of Rupelian Limestone According to Temperature

\begin{tabular}{lllll}
\hline Temperature $\left({ }^{\circ} \mathrm{C}\right)$ & \multicolumn{1}{c}{20} & \multicolumn{1}{c}{250} & 600 & 800 \\
\hline Modulus of elasticity $(\mathrm{GPa})$ & 2.5 & 2 & 2 & $1 \mathrm{e}-3$ \\
Poisson's ratio & 0.3 & 0.3 & 0.3 & 0.3 \\
Coefficient of thermal expansion $\left(\mathrm{K}^{-1}\right)$ & $2.10 \mathrm{e}-6$ & $1.6 \mathrm{e}-5$ & $1.6 \mathrm{e}-5$ & $1.6 \mathrm{e}-5$ \\
\hline
\end{tabular}

1) Longitudinal cross-section of the second gallery

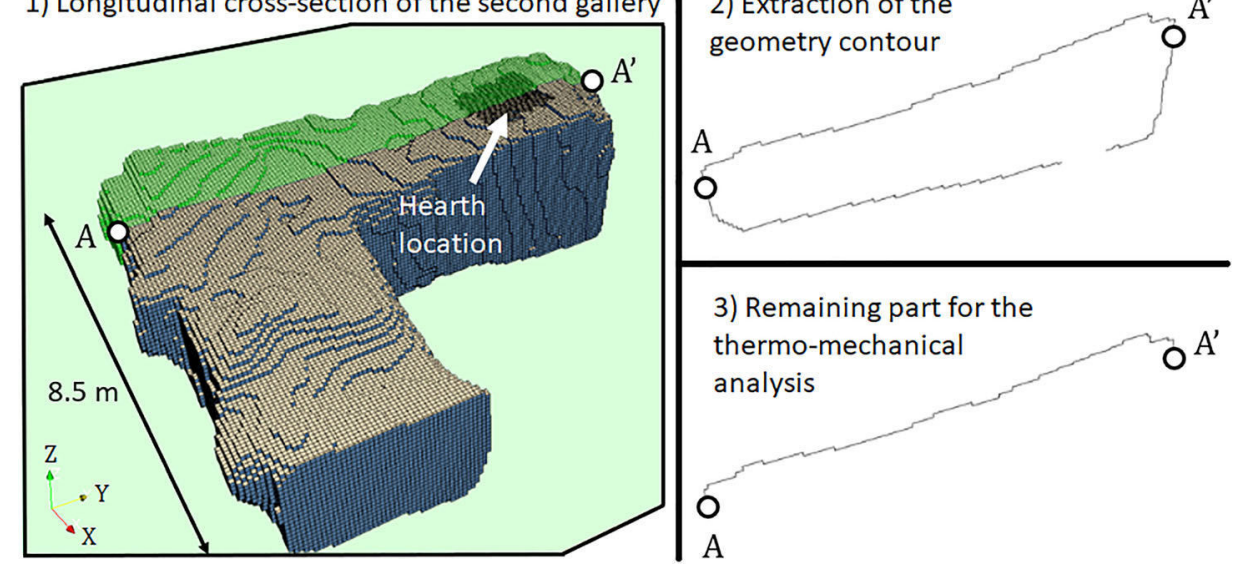

Figure 14. Sequences for the extraction of the infersection between the geometry and the cutting plane. Only the interesting part of the intersection is maintained.

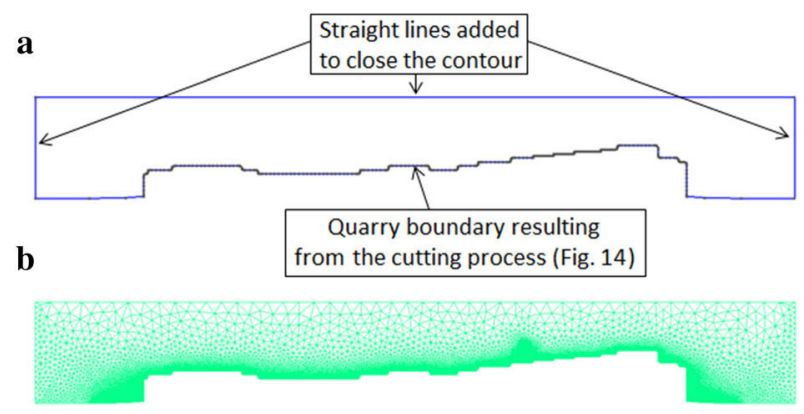

Figure 15. a The confour consists of the remaining part of the quarry and additional straight lines. $b$ Mesh of the surface inside the contour performed by GMSH [59].

Regarding the mesh, a 2D cutaway of the OpenFOAM mesh is created and only the boundary surface intersected by the cutting plan is kept (Fig. 14). Then, a contour composed of the boundary surface and straight lines is designed in order for the surface inside the contour to correspond to the rock mass (Fig. 15a). 
Because a mechanical investigation is conducted, right angles are prohibited. The cartesian mesh requires smoothing. The smoothing algorithm (Fig. 16) is itemised as follows:

- Smoothing occurs if an angle is greater than $80^{\circ}$.

- Two midpoints are created between A and B and between B and C.

- A third point $\mathrm{E}$ is introduced as described in Fig. 16. Trigonometry gives

- $\alpha=154^{\circ}$ and $\beta=218^{\circ}$.

Eventually, GMSH [59] achieves the mesh according to the user preferences for refinement (Fig. 15b). The study demands high refinement at walls because colour change processes often occur within only the first few millimetres. Then, the first cell size of the mesh in Fig. 15b is approximately $0.2 \mathrm{~mm}$.

A custom Python code manages all these procedures automatically. Another Python program handles the transfer of the boundary temperatures. For each boundary line in the 2D mesh, the program looks for the nearest boundary face in the $3 \mathrm{D}$ mesh and imposes the corresponding temperature on the boundary line. Both Python programs constitute the coupling between OpenFOAM and Cast $3 \mathrm{~m}$. They are freely available on GitHub [52].

A Neumann boundary condition (no temperature gradient) is imposed on the straight lines. The displacement is free at the wall surface but is set to zero for the straight lines to account for the remaining rock outside the simulated geometry. The self-weight of the rock is not considered.

\subsection{Comparison Between Experimentation and Simulation}

In the following section, right and left correspond to directions relative to a person with their back to the entrance (Fig. 17).

4.4.1. Colour Changes and Soot Deposit According to the criteria, the colour changes are linked to the surface temperature only. Therefore, the comparison between observations and simulations of color changes can be completed with the OpenFOAM simulation only. Figures 18 and 19 display this comparison in addi-

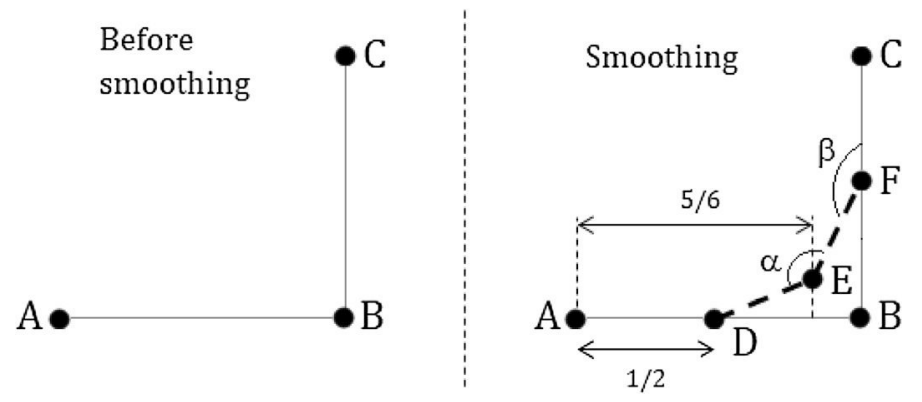

Figure 16. Smoothing process of a right angle (ABC). Three points (D, E and F) are created and the former path (ABC) becomes (ADEFC). 

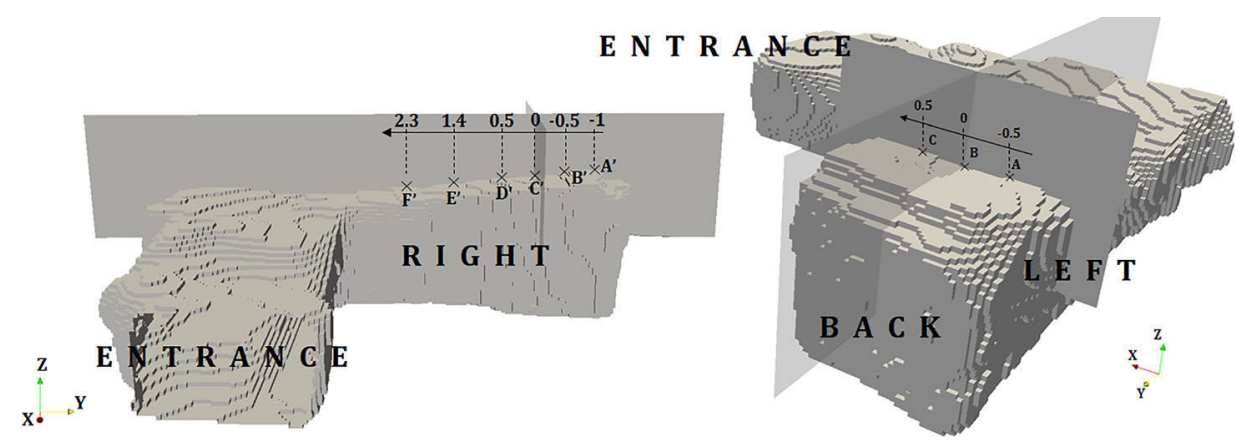

Figure 17. Conventional names of each wall and stress point locations in both mechanical simulations.

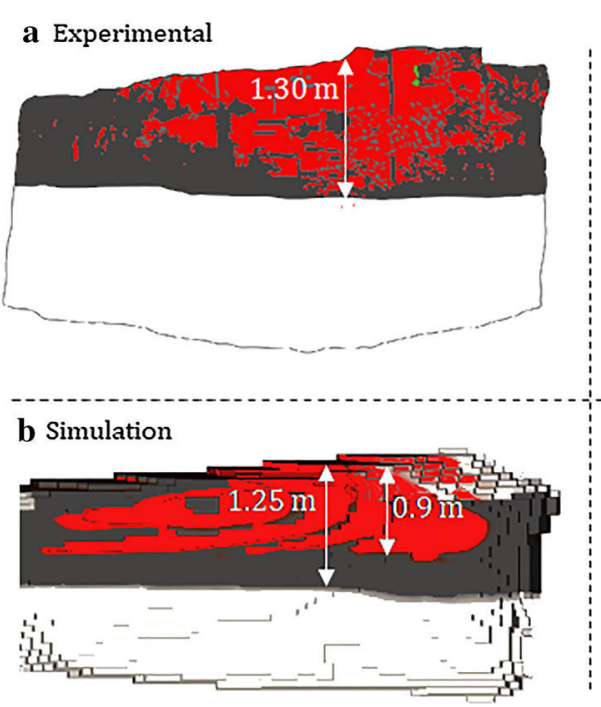

L E F T W A L L c Experimental
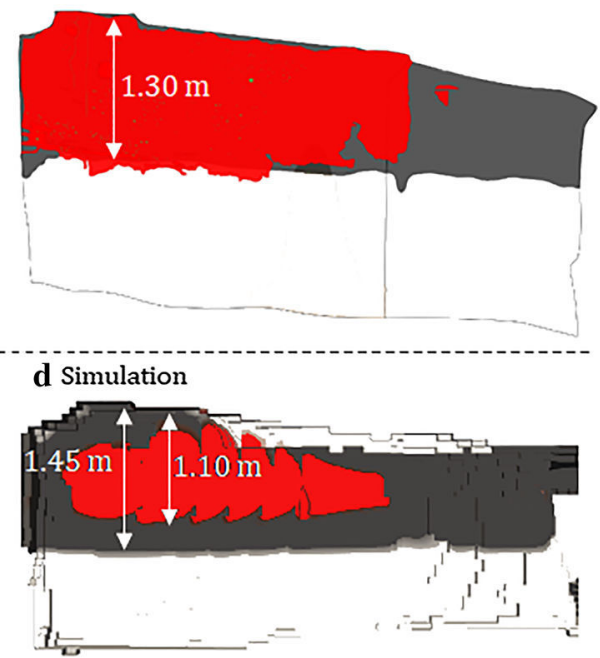

R I G H T W A L L

Figure 18. Comparison between the experiment and simulation for the left and right walls. Red corresponds to rubification, dark grey to soot deposition and green to spalling. a Experimental left wall. b Simulated left wall. c Experimental right wall. d Simulated right wall (Color figure online).

tion to that on the comparison of the soot deposits. Experimentally, rubification extends up to 2.60 metres from the fire centreline, and the upper part of the walls are fully rubified. The borderlines of the rubification and soot deposit are very close on the three walls. The ceiling is covered by soot from the fireplace to the entrance, so the borderlines do not correspond. The grey area with a $1.5 \mathrm{~m}$ diameter in Fig. 19a is centred above the fire and no such alteration occurs on the walls. 
a Experimental

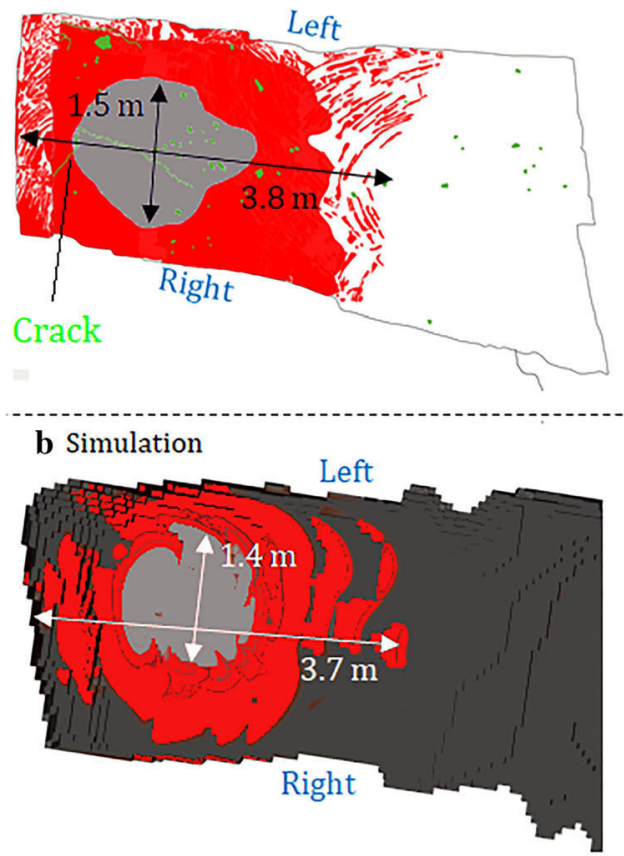

C E I L I N G c Experimental

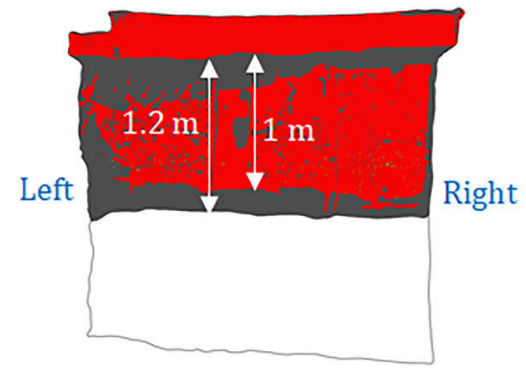

d Simulation

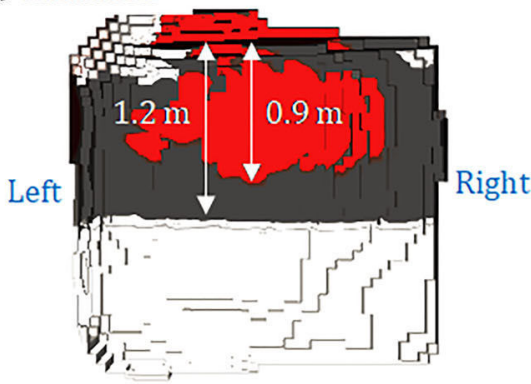

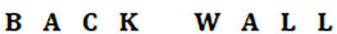

Figure 19. Comparison between the experiment and simulation for the back wall and ceiling. Red corresponds to rubification, light grey to grey color, dark grey to soot deposition and green to spalling. a Experimental back wall. b Simulated back wall. c Experimental ceiling. d Simulated ceiling (Color figure online).

OpenFOAM provides a satisfactory expansion of the rubification at every wall and the ceiling. The borderlines are very similar to the experimental ones. The impact on the ceiling is also consistent with the observations. This agreement means that the heat transfer modelling close to the fire is rather accurate. For instance, the ceiling above the hearth received between $10 \mathrm{~kW} \mathrm{~m}^{-2}$ and $20 \mathrm{~kW} \mathrm{~m}^{-2}$ $10 \mathrm{~min}$ after ignition. These values seem to be in a reasonable range for such a fire. The simulated grey area is, however, located closer to the left wall, whereas the experimental geay zone is actually centred. According to Figs. 4 and 5, it is warmer on the left than on the right, so the displacement of the grey alteration appears relevant. The difference could stem from observational uncertainties due to the difficulty of visual surveying because of soot cover. The flame structure could also explain the offset. The tepee shape of the wood hearth may have a centring function during the experiment, which does not exist in the simulation. The simulated deposition of soot agrees with the experimentation since both numerical and experimental soot deposit limits match. The soot deposits are not presented in Fig. 19a, b because the ceiling is fully covered by soot in both cases. 
The corners between the ceiling and walls are not rubified in the simulation, which is not consistent with the experimental result. Instead, the observations display rubification near the corners and nothing very near them. The zone without alteration in the experimentation is then smaller than the corresponding simulated zone. Actually, the grid size does not allow the simulation of the convective transport until these corners. A finer mesh in the corners would be necessary to account for this effect.

The vertical spread of rubification on walls is underestimated by the simulation. This disagreement is consistent with the results of the prior section about the hot layer thickness. In the fire zone, the numerical hot layer is thinner, so a larger part of the walls remains unaffected.

4.4.2. Spalling Two simulations are performed in the planes $\mathrm{xOz}$ (Fig. 20) and $\mathrm{yOz}$ (Fig. 21), where $\mathrm{O}$ is the centre of the hearth. Because spalling is a buckling process, the study focuses on compressive stresses along the walls. According to measurements on Rupelian samples [20], the compressive strength of this limestone is approximately $1.96 \mathrm{MPa}$ at $20^{\circ} \mathrm{C}$ and $2.33 \mathrm{MPa}$ at $300^{\circ} \mathrm{C}$. Thus, every area in dark blue in Figs. 20 and 21 is beyond the strength threshold and likely to spall. The risk of spalling remains important from the fireplace to the intersection between the galleries. Nonetheless, the spalling depth is higher above the fire because the compressive stress can reach the compressive strength up to $3 \mathrm{~cm}$ from the surface.

An analysis of the compressive stresses in the quarry walls during the fire is conducted for several points in both planes (Fig. 17). Three depths are considered: the surface $(0.2 \mathrm{~mm}), 1 \mathrm{~cm}$ and $3 \mathrm{~cm}$ (Figs. 22, 23, 24).

Since the limestone in the first millimeter from the surface of the ceiling is very warm, the surface compressive stress is much higher than the compressive strength (approximately $2 \mathrm{MPa}$ for this temperature range) at all the locations. Mechanical stresses then explain the great number of superficial spallings (a few millimetres). One centimetre within limestone, the compressive stress also exceeds the fracture threshold in most of the ceiling, until location $\mathrm{F}^{\prime}$ (Fig. 24). After this location,

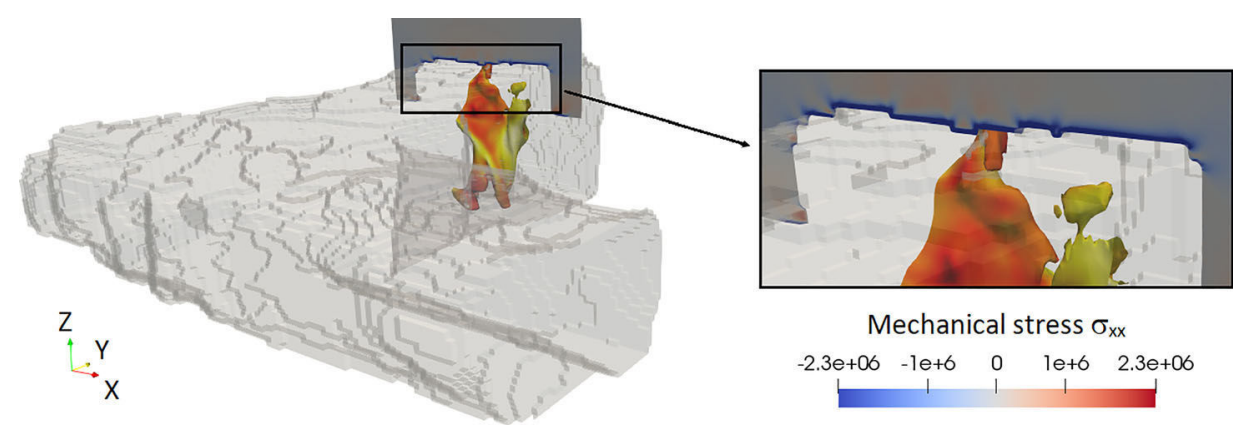

Figure 20. Compressive stresses $\left(\sigma_{x x}\right)$ computed by 2D simulations in the quarry walls 45 min after ignition. The simulation is performed with Cast $3 \mathrm{~m}$ in the plane $\times \mathrm{Oz}(0$ is the centre of the fire). 


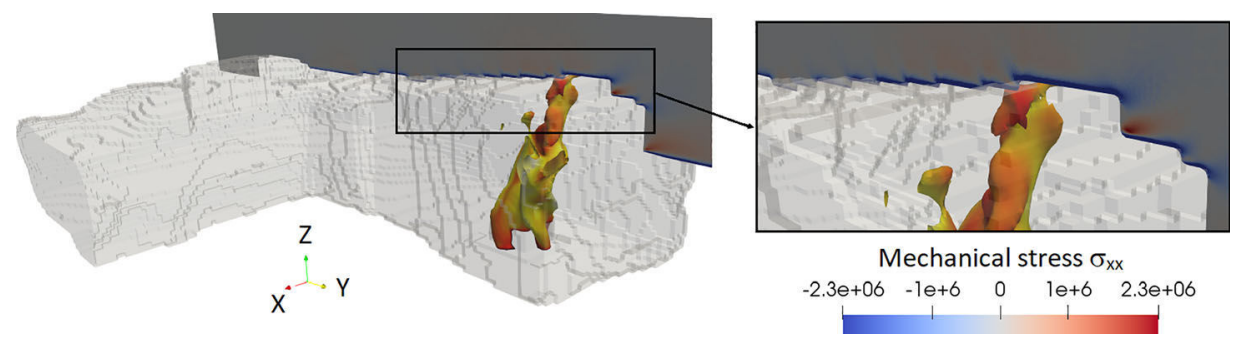

Figure 21. Compressive stresses $\left(\sigma_{y y}\right)$ computed by 2D simulations in the quarry walls $45 \mathrm{~min}$ after ignition. The simulation is performed with Cast3 $\mathrm{m}$ in the plane yoz.

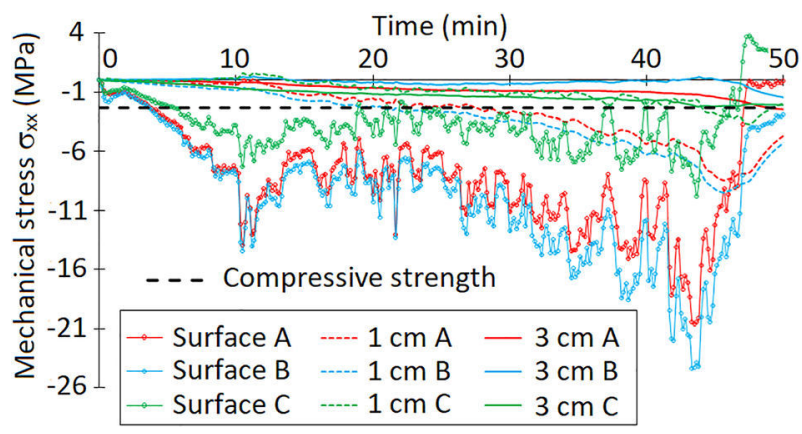

Figure 22. Evolution of the compressive stresses $\left(\sigma_{\mathbf{x x}}\right)$ in the quarry walls (surface, $1 \mathrm{~cm}$ and $3 \mathrm{~cm}$ deep) during the fire. The locations from $A$ to $C$ are defined in Fig. 17.

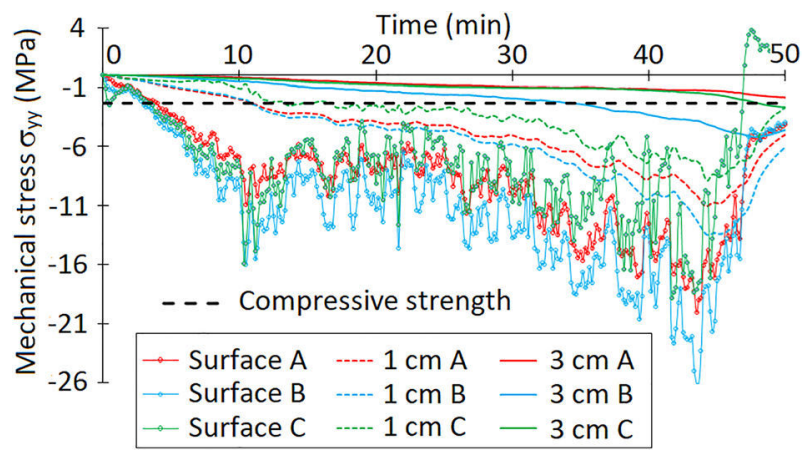

Figure 23. Evolution of the compressive stresses $\left(\sigma_{y y}\right)$ in the quarry walls (surface, $1 \mathrm{~cm}$ and $3 \mathrm{~cm}$ deep) during the fire. The locations from $A^{\prime}$ to $C^{\prime}$ are defined in Fig. 17. 


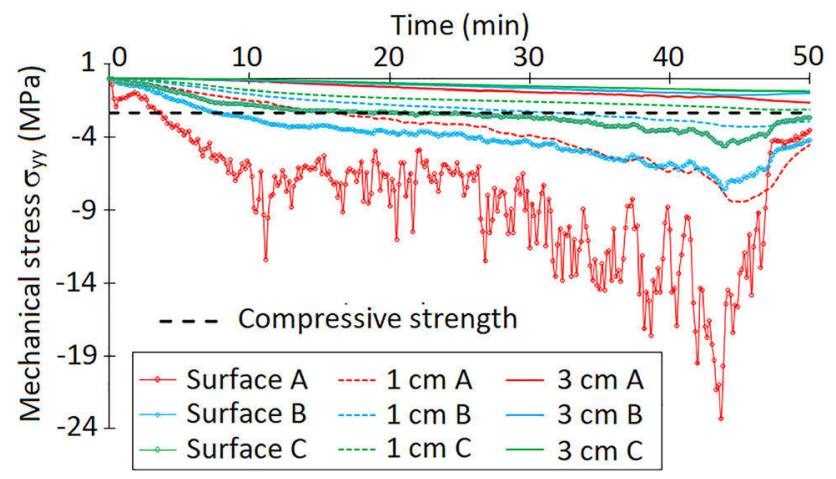

\section{Figure 24. Evolution of the compressive stresses $\left(\sigma_{y y}\right)$ in the quarry walls (surface, $1 \mathrm{~cm}$ and $3 \mathrm{~cm}$ deep) during the fire. The locations from $D^{\prime}$ to $F^{\prime}$ are defined in Fig. 17.}

superficial spallings can still occur because the stresses remain high in the first centimetre. Three centimetres deep in rock, the compressive stresses remain weak and less than the compressive strength except just behind the fire. The curve relating to location $\mathrm{B}^{\prime}$ in Fig. 23 indeed displays a stress greater than $4 \mathrm{MPa}$. The thermomechanical impact is more significant near this region because of the proximity to the fire and the strong containment at the back of the quarry.

Figure 22 reveals that the left side is much more impacted than the right side. This result is consistent with the offset to the left of the grey area (Fig. 19b) and the higher temperatures near tree T2 than tree T1 (Figs. 4, 5). The compressive stresses along $\mathrm{X}$ (Fig. 22) are higher just above the fire but not along the $\mathrm{Y}$ axis (Fig. 24). The compressive stresses along $\mathrm{Y}$ are higher at $0.5 \mathrm{~m}$ from the fire centreline (at $\mathrm{B}^{\prime}$ and $\mathrm{D}^{\prime}$ ). These higher values result from the high gas temperature gradients around the fire. Since the gases are much colder out of the flame than within it, the limestone does not expand equally in both regions. Then, the region outside the flame restrains the expansion of limestone impacted by very hot gases. High compressive stresses therefore occur at the borderline between these areas. At $\mathrm{B}^{\prime}$, this effect is then combined with the confinement. This area is therefore the most constrained.

According to the mechanical analysis, the spalling probability is thus greater on the left side and around the flames. Experimentally, spalling occurs mostly to the left (Fig. 19c) and near the fire. There are few spallings above the fire, which agrees with the conclusion of the prior analysis. Moreover, spalling experimentally occurs from the fireplace to the intersection between the galleries and is replicated by the simulation. However, spalling does not occur behind the fire, even though the stresses there are the greatest. This discrepancy might be explained by the formation of a crack, as indicated in Fig. 19a, which could allow the release of enough energy to avoid spallings. 


\section{Conclusion}

The thermal marks discovered on the walls of the Chauvet-Pont d'Arc Cave raise archaeological questions about the intensities and functions of such fires made deep in the cavity. To provide answers for the archaeological community, an investigation is conducted to evaluate the characteristics of the fires that may have caused these alterations. In this context, an experiment consisting of three identical fires is achieved over 3 days inside a former underground limestone quarry. This project aims to experimentally reproduce thermal marks similar to those in the Chauvet-Pont d'Arc Cave and acquire experimental data to validate a numerical model.

This article validates the results of the numerical model with the experimental data and observations. The comparison involves temperatures, gas and particle concentrations, velocities, soot deposition and thermal marks. The observations include the changes in the colour of the limestone due to high-temperature chemical reactions and spallings.

To model all the phenomena, a numerical coupling between OpenFOAM and Cast $3 \mathrm{~m}$ is set up. OpenFOAM allows the simulation of combustion and gas circulation, while Cast $3 \mathrm{~m}$ manages the thermo-mechanical matter in the rock mass. The coupling between these two programs consists of two Python scripts that ensure the transition from the $3 \mathrm{D}$ geometry of the quarry to the $2 \mathrm{D}$ geometry of rock mass sections.

The numerical modelling gives results that are in agreement with the experiment despite small discrepancies, which are usual for this kind of complex simulation. Overall, OpenFOAM provides a consistent description of the environment inside the quarry. However, the hot layer remains difficult to evaluate by the model and some errors can jeopardize the simulated temperatures. Likewise, the gas and particle concentrations suffer from errors in the evaluation of the hot layer thickness. The thermal impacts are also well reproduced by the simulation because the extent of the colour changes broadly agrees with the observations. Only the expansion of rubification is faintly underestimated on the vertical walls. Moreover, the numerical deposition of soot matches the visual surveys, even if the amount of particles is uncertain. Finally, the spalling distribution conforms to the trends computed by the thermomechanical study.

Previous works [22] and the present article constitute the numerical model that will be used for the simulations in the geometry of the Chauvet-Pont d'Arc Cave. This model will enable the simulation of several fire scenarios and provide the most likely characteristics of the fires that caused the thermal marks. More generally, the numerical coupling could be applied to other issues where the interaction between fires and the surrounding solid structures is critical (tunnels, mines, buildings, etc.). This simulation can indeed predict mechanical damage according to the power of the fire. This work can thus be applied to post-fire analysis when only the mechanical damage and soot deposition are available to assess the characteristics of a fire. 


\section{Acknowledgements}

We thank the Regional Council of Aquitaine and Nouvelle-Aquitaine for providing funding for the CarMoThap project and for their investment in a 432-processor cluster located in the I2M laboratory. The researches on the Chauvet-Pont d'Arc Cave have received specific financial help from the Ministry of Culture and Communication. We thank the LCPP staff (Laboratoire Centrale de la Préfecture de Police) for their help in providing the experimental instrumentation (velocity sensors, thermocouples, gas and particle concentration sensors). Furthermore, the following institutions have given support: CNRS, Bordeaux University, BordeauxINP and Bordeaux-Montaigne University. We thank C. Bouchet, the owner of the quarry in Fauroux (Lugasson) and M. Vidal for having made available scots pine, as well as the SDIS 33 staff for participation in the experiments of the CarMoThaP program. We also express our gratitude to M. Corbé, L. Bassel, M. Bosq, E. Florensan, J. Sabidussi and C. Verdet for their precious help packaging wood and for their involvement in the November 2016 experiments. This work was also performed using HPC resources from GENCI-CINES (Grant 2017A0032B10268).

\section{References}

1. Zadeh S, Maragkos G, Beji T, Merci B (2016) Large eddy simulation of the ceiling jet induced by the impingement of a turbulent air plume. Fire Technol 52(6):2093-2115

2. Le D, Labahn J, Beji T, Devaud C, Weckman E, Bounagui A (2018) Assessment of the capabilities of FireFOAM to model large-scale fires in a well-confined and mechanically ventilated multi-compartment structure. J Fire Sci 36(1):3-29

3. Yuan S, Zhang J (2009) Large eddy simulation of compartment fire with solid combustibles. Fire Saf J 44(3):349-362

4. Weisenpacher P, Glasa J, Halada L (2016) Parallel Computation of smoke movement during a car park fire. Comput Inform 35:1416-1437

5. Zhang X, Guo Y, Chan C, Lin W (2007) Numerical simulations on fire spread and smoke movement in an underground car park. Build Environ 42(10):3466-3475

6. Roh J, Ryou H, Kim D, Jung W, Jang Y (2007) Critical velocity and burning rate in pool fire during longitudinal ventilation. Tunn Undergr Space Technol 22(3):262-271

7. Zhao S, Liu F, Wang F, Weng M, Zeng Z (2018) A numerical study on smoke movement in a metro tunnel with a non-axisymmetric cross-section. Tunn Undergr Space Technol 73:187-202

8. McGrattan K, Hostikka S, McDermott R, Floyd J, Weinschenk C, Overholt K (2013) Fire dynamics simulator user's guide, sixth edition 1019. NIST Special Publication (Online). https://pages.nist.gov/fds-smv/manuals.html

9. Li J, Chow W (2003) Numerical studies on performance evaluation of tunnel ventilation safety systems. Tunn Undergr Space Technol 18(5):435-452

10. Meng N, Hu L, Wu L, Yang L, Zhu S, Chen L, Tang W (2014) Numerical study on the optimization of smoke ventilation mode at the conjunction area between tunnel track and platform in emergency of a train fire at subway station. Tunn Undergr Space Technol 40:151-159 
11. Zhao B, Kruppa J (2002) Structural behaviour of an open car park under real fire scenarios. Fire Mater 28:269-280

12. Luo C, Xie W, DesJardin P (2011) Fluid-structure simulations of composite material response for fire environments. Fire Technol 47(4):887-912

13. Khoury G (2000) Effect of fire on concrete and concrete structures. Prog Struct Eng Mater Banner 2(4):429-447

14. Zhang H, Davie C (2013) A numerical investigation of the influence of pore pressures and thermally induced stresses for spalling of concrete exposed to elevated temperatures. Fire Saf J 59:102-110

15. Bordard A, Guibert P, Ferrier C, Debard E, Kervazo B, Geneste J (2014) Les rubéfactions des parois de la grotte Chauvet: une histoire de chauffe? In: Les arts de la Préhistoire: micro-analyses, mises en contextes et conservation, Paillet P. (dir)

16. Debard E, Ferrier C, Kervazo B (2012) Etude géologique de la grotte Chauvet-Pont d'Arc. Bilan des travaux de la triennale 2010-2012. Etudes pluridisciplinaires à la grotte Chauvet-Pont d'Arc (Ardèche). Rapport d'activité 2010-2012, vol 1, pp 59-98

17. Quiles A, Valladas H, Bocherens H, Delque-Kolic E, Kaltnecker E, Plicht J, Delannoy J-J, Feruglio V, Fritz C, Monney J, Philippe M, Tosello G, Clottes J, Geneste J-M (2016) A high-precision chronological model for the decorate Upper Paleolithic cave of Chauvet-Pont d'Arc, Ardèche, France. Proc Natl Acad Sci 113(17):4670-4675

18. Guibert P, Brodard A, Quilès A, Geneste J-M, Baffier D, Debard E, Ferrier C (2015) When were the walls of the Chauvet-Pont-d'Arc Cave heated? A chronological approach by thermoluminescence. Quat Geochronol 29:36-47

19. Ferrier C, Debard E, Kervazo B, Brodard A, Guibert P, Baffier D, Feruglio V, Gely B, Geneste J, Maksud F (2014) Les parois chauffées de la grotte Chauvet-Pont d'Arc (Ardèche): caractérisation et chronologie. Paléo 25:59-78

20. Lacanette D, Mindeguia J-C, Brodard A, Ferrier C, Guibert P, Leblanc J-C, Malaurent P, Sirieix C (2017) Simulation of an experimental fire in an underground limestone quarry for the study of Paleolithic fires. Int J Therm Sci 120:1-18

21. Salmon F, Lacanette D, Mindeguia J-C, Sirieix C, Ferrier C, Leblanc J-C (2018) FireFOAM simulation of a localised fire in a gallery. J Phys Conf Ser 1107:042017

22. Salmon F, Lacanette D, Mindeguia J-C, Sirieix C, Bellivier A, Ferrier C, Leblanc J-C (2019) Localized fire in a gallery: model development and validation. Int $\mathbf{J}$ Therm Sci 139:144-159

23. OpenFOAM (Online). http://www.openfoam.org/

24. FireFOAM (Online). http://www.fmglobal.com/modeling

25. CAST3M (2016) (Online). http://www-cast3m.cea.fr

26. Théry-Parisot I, Thiébault S (2005) Analyses polliniques des sols aurignaciens de la grotte Chauvet (Ardèche). In: Geneste (dir) J-M (ed) La grotte Chauvet à Vallon-Pontd'Arc: un bilan des recherches pluridisciplinaires. Actes de la séance de la Société préhistorique française, Lyon, 2003, Paris

27. Bellivier A, Coppalle A, Loo A, Yon J, Decoster L, Dupont S, Bazin H (2015) Comparison and assessment of particle mass concentrations measurements in fire smokes with a microbalance, opacimeter and PPS devices. In: 10th AOSFST, October 5-7, Tsukuba

28. Luo M (1997) Effects of radiation on temperature measurement in a fire environment. J Fire Sci 15(6):443-460

29. Dréan V, Auguin G, Leblanc J-C, Lacanette D, Mindeguia J-C, Bellivier A, Ferrier C (2017) Numerical modelling of thermal conditions during fires in cave-like geometry. In: Proceedings of the 15th international conference fire and materials, pp 64-65 
30. Chase J (1998) NIST-JANAF thermochemical tables, fourth edition. J Phys Chem Ref Data, Mongraph No. 9

31. Poling B, Prausnitz J, O'Connell J (1987) The properties of gases and liquids. McGrawHill, New York

32. Sutherland W (1893) The viscosity of gases and molecular force. Philos Mag S5:507531

33. Magnussen B, Hjertager B (1977) On mathematical modeling of turbulent combustion with special emphasis on soot formation and combustion. Proc Combust Int 16:719729

34. Yoshizawa A (1986) Statistical theory for compressible turbulent shear flows, with the application to subgrid modeling. Phys Fluids 29(7):2152-2164

35. Tihay V, Perez-Ramirez Y, Morandini F, Santoni P, Barboni T (2013) Heat transfers and energy released in the combustion of fine vegetation fuel beds. 21ème Congrès Français de mécanique

36. Grosshandler W (1993) A narrow-band model for radiation calculations in a combustion environment. NIST technical note 1402

37. Beresnev S, Chernyak V (1995) Thermophoresis of s spherical particle in a rarefied gas: numerical analysis based on the model kinetic equations. Phys Fluids 7:1743-1756

38. Sagot B, Antonini G, Buron F (2009) Annular flow configuration with high deposition efficiency for the experimental determination of thermophoretic diffusion coefficients. $\mathbf{J}$ Aerosol Sci 40(12):1030-1049

39. Brugière E (2012) PhD thesis, INSA (Rouen)

40. SnappyHexMesh (Online). https://openfoam.org/?s= snappyhexmesh

41. Alpert R (2008) SPFE handbook of fire protection engineering, Chapter Ceiling Jet Flows, 4th edn. National Fire Protection Association, Quincy

42. You H, Faeth G (1979) Ceiling heat transfer during fire plume and fire impingement. Fire Mater 3(3):140-147

43. Holman J (1990) Heat transfer, 7th edn. McGraw-Hill, New York

44. Vilfayeau S, Ren N, Wang Y, Trouvé A (2015) Numerical simulation of under-ventilated liquid-fueled compartment fires with flame extinction and thermally-driven fuel evaporation. Proc Combust Inst 35(3):2563-2571

45. Maragkos G, Beji T, Merci B (2017) Advances in modelling in CFD simulations of turbulent gaseous pool fires. Combust Flame 181:22-38

46. Le V, Marchand A, Verma S, White J, Marshall A, Rogaume T, Richard F, Luche J, Trouvé A (2018) Simulations of a turbulent line fire with a steady flamelet combustion model and non-gray gas radiation models. J Phys Conf Ser 1107:042009

47. Chatterjee P, Meredith K, Wang Y (2017) Temperature and velocity distributions from numerical simulations of ceiling jets under unconfined, inclined ceilings. Fire Saf $\mathbf{J}$ 91:461-470

48. Ren N, Wang Y, Vilfayeau S, Trouvé A (2016) Large eddy simulation of turbulent vertical wall fires supplied with gaseous fuel through porous burners. Combust Flame 169:194-208

49. Cooper L (1988) Ceiling jet-driven wall flows in compartment fires. Combust Sci Technol 62(4-6):285-296

50. McCaffrey B, Heskestad G (1976) A robust bidirectional low-velocity probe for flame and fire application. Combust Flame 26:125-127

51. Overholt K, Floyd J, Ezekoye O (2016) Computational modeling and validation of aerosol deposition in ventilation ducts. Fire Technol 52(1):149-166

52. Coupling OpenFOAM — Cast3m (2019) (Online). https://github.com/FabienSalmon/Cou plage.git 
53. Liedgren L, Hörnberg G, Magnusson T, Östlund L (2017) Heat impact and soil colors beneath hearths in northern Sweden. J Archaeol Sci 79:62-72

54. Aldeias V, Dibble H, Sandgathe D, Goldberg P, McPherron S (2016) How heat alters underlying deposits and implications for archaeological fire features: a controlled experiment. J Archaeol Sci 67:64-79

55. Ruan H, Frost R, Kloprogge J, Duong L (2002) Infrared spectroscopy of goethite dehydroxylation: III. FT-IR microscopy of in situ study of the thermal transformation of goethite to hematite. Spectrochim Acta Part A 58:967-981

56. Borg R, Hajpal M, Török A (2013) The fire performance of limestone, vol 6. Application of Structural Fire Engineering

57. Ferrier C, Debard E, Kervazo B, Brodard A, Guibert P, Baffier D, Feruglio V, Gely B, Geneste J, Maksud F (2014) Les parois chauffées de la grotte Chauvet-Pont d'Arc (Ardèche): caractérisation et chronologie. PALEO 25

58. Preston F, White H (1938) Observations on spalling. J Am Ceram Soc 17:137-144

59. Geuzaine C, Remacle J (2009) Gmsh: a 3-D finite element mesh generator with built-in pre- and post-processing facilities. Int J Numer Methods Eng 79(11):1309-1331

Publisher's Note Springer Nature remains neutral with regard to jurisdictional claims in published maps and institutional affiliations. 